ESTUDIO

\title{
DISCRIMINACIÓN DE PRECIOS SIN PODER DE MERCADO*
}

\author{
Michael E. Levine
}

\begin{abstract}
Políticos, reguladores y analistas de la legislación antimonopolio han utilizado frecuentemente la presencia de la discriminación de precios como indicador de poder de mercado. Suelen estar motivados por las presiones políticas que ejercen los compradores afectados por el
\end{abstract}

Michael E. Levine. B. A. (Filosofía), Reed College; J. D. y LL. B, Yale Law School. Profesor e Investigador Ilustre (Distinguished Research Scholar) de la Facultad de Derecho de New York University. Anteriormente fue decano de la Escuela de Administración de Yale (1988-1992), miembro de las facultades de Derecho de Harvard (1999-2002) y Yale (2002-2005) y profesor visitante en MIT, The London School of Economics y Duke University. Durante los años ochenta y noventa desempeñó altos cargos directivos en la industria aeronáutica y se le ha reconocido como uno de los diez pioneros más influyentes de la historia de la aviación comercial. En su condición de académico y funcionario público tuvo una destacada participación en el diseño de los mecanismos y prácticas que se usaron en la desregulación del transporte aéreo en Estados Unidos en los años setenta.

Agradezco a Richard Craswell, Einer Elhauge, David Friedman, Andy Hansen, Henry Hansmann, Daniel Kasper, Louis Kaplow, Lewis Komhauser, Kristin Madison, Ariel Pakes, Alan Schwartz, Matthew Spitzer y a los participantes en talleres realizados en Harvard, Yale, Stanford y la Universidad de Nueva York por sus útiles comentarios a anteriores borradores y presentaciones. Las observaciones de Alan Schwartz fueron particularmente provechosas en lo relativo al carácter único del equilibrio de precios y, como se señala más adelante, David Friedman proporcionó un importante ejemplo. Richard Craswell aportó comentarios de inestimable valor sobre una serie de aspectos. Pese a toda esta ayuda, de todos modos persisten errores. Huelga advertir que los asumo como propios.

* "Price Discrimination without Market Power" apareció en Yale Journal of Regulation, Vol. 19, No 1, 2002. Derechos reservados, Michael Levine, 2002. Su traducción al castellano y reproducción en esta edición cuentan con la debida autorización. Estudios Públicos agradece a Francisca Dussaillant por la revisión de la traducción y a Alberto Ide por haber realizado la traducción preliminar. 
más alto de los precios discriminatorios para que se regule esta situación o se apliquen sanciones antimonopolio en las industrias donde se discriminan precios. La justificación para actuar de esa manera la encuentran en modelos económicos donde se equipara la desviación del costo marginal con el poder de mercado. En el caso inusual de que los costos sean completamente separables, esta postura puede resultar válida. Sin embargo, en la mayoría de los casos los bienes y servicios del mundo real son producidos bajo condiciones en que los costos (hundidos o no), como los de investigación y desarrollo (I + D), publicidad, producción o distribución (como por ejemplo las instalaciones comunes), son compartidos con otros productos. Bajo estas condiciones comunes, las empresas cuya capacidad para generar rentas monopólicas se ve limitada por la competencia adoptarán la discriminación de precios como la estrategia óptima para repartir los costos comunes entre los compradores. Si bien es cierto que lo anterior permite muchas veces aumentar el bienestar (ventaja de la que, según sugiere la tarificación de Ramsey, gozan algunos monopolistas), ello no es evidencia de que el poder unilateral o colusivo afecte la cantidad producida por la industria, condición que constituye la esencia de los conceptos de "poder monopólico” o “poder de mercado”. Una versión de la discriminación de precios también puede emplearse para recuperar los costos hundidos en un ambiente competitivo, aportando así una solución al problema de la "competencia destructiva" que ha proliferado en la economía regulatoria desde fines del siglo 19 hasta las postrimerías del siglo 20. Esta visión de la discriminación de precios sirve, asimismo, para explicar y justificar la práctica de la fijación de precios de red, que ha sido tildada de predatoria. Por cierto que se puede recurrir a la discriminación de precios para facilitar y preservar el poder de mercado. Pero si bien algunos vendedores que discriminan los precios pueden generar rentas monopólicas, esta práctica por sí sola no constituye evidencia de poder de mercado y no debería aducirse para justificar una intervención regulatoria.

\section{Introducción}

L.

discriminación de precios suele causar molestia entre los compradores perjudicados y motiva la intervención de los reguladores. Los compradores se quejan cuando ven que para satisfacer sus necesidades de consumo particulares deben pagar precios superiores y aparentemente de márgenes más altos que los pagados por otras personas para satisfacer necesidades similares. Y su protesta encierra por lo general la sugerencia de 
que sólo un monopolio o una conspiración se interponen entre ellos y los precios más bajos y que alguien debe hacer algo al respecto. Ese "alguien" es comúnmente un político que actúa por intermedio de un regulador o fiscal público, a quien se le solicita intervenir con miras a eliminar la discriminación de precios o la estructura de mercado que presuntamente le sirve de sustento. Los economistas del mundo académico a menudo respaldan la postura de los compradores, imaginando que el poder de mercado es la fuerza oculta detrás de la discriminación de precios, y consideran que, aun cuando ella puede ser una manera eficiente de atenuar los efectos del poder de mercado, la eliminación del poder de mercado constituye una vía más segura hacia la eficiencia.

Por ejemplo, al mismo tiempo que la desregulación de las aerolíneas ha permitido que el mercado de las aerolíneas sea por lo general competitivo, las estructuras tarifarias de estas empresas se han vuelto más complejas. La activa segmentación del mercado se ha convertido en una práctica habitual en la mayor parte del sector de las aerolíneas, tal como sucede en la telefonía y en otros negocios que operan en red, y su existencia ha dado lugar a debates en torno a cuán competitiva es la industria desregulada de las aerolíneas. Esta discriminación de precios ha dado pie a acusaciones de ejercer un poder de mercado persistente (centradas particularmente en los "nodos" o centros de distribución regionales) y a llamados a favor de un mayor grado de intervención estatal para reducirlo o eliminarlo. Los ejecutivos de aerolíneas han respondido señalando, entre otras cosas, que la rentabilidad del capital sigue siendo inferior al promedio, lo cual a juicio de ellos debería considerarse como evidencia de que la industria es competitiva.

Obviamente que no todas las segmentaciones de precios en las aerolíneas son discriminatorias. Algunas diferencias de precios en los pasajes aéreos y de otros medios de transporte están respaldadas por diferencias en el costo de los productos, y otras por diferencias en el costo de oportunidad. Pero muchas no. En vista de que la segmentación de precios en la industria aeronáutica ha dado lugar a acusaciones de prácticas predatorias y ha motivado propuestas regulatorias ${ }^{1}$, y puesto que dichas acusaciones y reacciones tienen alcances implícitos más amplios, es preciso comprender con mayor claridad las complicadas estructuras de fijación de precios con que se segmenta el mercado.

\footnotetext{
${ }^{1}$ Véase, por ejemplo, la propuesta del US. Department of Transportation (Departamento Estadounidense de Transporte) para regular las reacciones competitivas de las aerolíneas con el objeto de fomentar la competencia y así eliminar el poder de mercado que presuntamente servía de respaldo para cobrar tarifas altas en los nodos. 63 Fed. Reg. 17, 919-1922 (10 de abril de 1998).
} 
Las estructuras de fijación de precios concebidas para lograr la segmentación no se limitan al rubro de las aerolíneas. Pueden encontrarse en otras áreas de la economía, en servicios como restoranes y hoteles, y en complejos productos manufacturados como automóviles y computadores. De hecho, probablemente se trate de estructuras más bien típicas que inusuales. Este fenómeno ha sido vastamente malentendido, incluso entre algunos economistas, en parte porque la formulación clásica de la teoría económica ha definido como mercados eficientes a aquellos que fijan precios a costo marginal, y en parte porque la discriminación de precios ha sido abordada de manera más explícita en monopolios naturales o en industrias reguladas a raíz de alguna denuncia de deficiencia en el mercado. También causa confusión el hecho de que algunas de las técnicas destinadas a extraer mayores rentas de algunos tipos de clientes más que de otros aparecen como una modalidad tradicional de discriminación de precios (distintos precios para el “mismo” producto), y otras operan de la misma manera al diseñar y utilizar variaciones de productos para segmentar mercados. Una percepción más clara de cuán generalizadas se encuentran las diversas formas de discriminación de precios, y de su relación con la competencia, permitirá mejorar las políticas públicas y arrojará luz sobre deficiencias de la actual teoría económica.

\section{EL PROBLEMA VISTO DESDE UNA PERSPECTIVA HISTÓRICA}

Al reflexionar sobre la discriminación de precios los economistas han elaborado históricamente el siguiente argumento: en un mercado competitivo, el precio equivale al costo marginal. Dondequiera que exista discriminación de precios, el precio se aparta del costo marginal. En consecuencia, si hay discriminación de precios, el mercado no es competitivo y existe poder de mercado. En la formulación histórica, entonces, los economistas suelen señalar a continuación que, como el poder de mercado ya existe, la discriminación de precios puede favorecer el crecimiento de la producción y, por tanto, no ser necesariamente perniciosa ${ }^{2}$. A decir verdad, muchas veces resulta deseable. Con todo, persiste la presunción generalizada de que la existencia de discriminación de precios lleva implícita la existencia de poder de mercado.

${ }^{2}$ Un interesante primer paso en la tarea de modificar sistemáticamente este argumento puede encontrarse en la obra de J. M. Clark, quien asocia de manera explícita la discriminación de precios con la eficiencia en mercados normalmente competitivos, pero no aclara si se requiere poder de mercado para respaldarla. Clark, J. M.: Studies in the Economics of Overhead Costs (1923), p. 417. 
Esta formulación resulta peligrosa cuando la manejan quienes diseñan políticas económicas. La discriminación de precios es por lo general impopular, al menos entre aquellos que pagan el precio más alto. Y la existencia de poder de mercado es ineficiente, por cuanto supone un estado de cosas en el que los productores se benefician por la vía de reducir la cantidad producida y distorsionar las señales de precios para los compradores, si se compara con la situación que prevalecería en condiciones de competencia. Así pues, la presión política que genera el resentimiento a causa de la discriminación de precios suele expresarse a través de llamados a adoptar medidas que eliminen el poder de mercado que supuestamente está detrás de ella. Y dado que la regulación perfecta es tan poco común como los mercados perfectos, esas medidas pueden fácilmente producir resultados peores que los que se pretendía corregir. Esta regulación imperfecta se torna en un problema particular cuando el poder de mercado no existe. Especialmente perniciosas resultan las medidas destinadas a eliminar la discriminación de precios y que procuran aminorar de este modo los efectos del aparente poder de mercado mediante el control de uno de sus síntomas. Por motivos que se analizan más adelante, estas medidas producen casi siempre resultados menos eficientes que los que se pretendía modificar.

Nótese que el debate histórico depende en gran medida de la asociación de la discriminación de precios con el poder de mercado (a menudo modelado como competencia monopólica u oligopolio) y con las presuntas ineficiencias que éste trae aparejadas. Sin embargo, hace ya largo tiempo que los economistas han comprendido que, allí donde hay poder de mercado, la discriminación de precios suele aumentar la eficiencia ${ }^{3}$. En efecto, puede aminorar o eliminar los incentivos a reducir la producción que surgen cuando hay poder de mercado. Es un lugar común de la teoría económica el que un monopolista capaz de discriminar perfectamente los precios no reducirá la producción y por tanto no causará ineficiencia (una "perdida de

${ }^{3}$ Katz desafía la postura convencional al sostener que la discriminación de precios en mercados monopólicamente competitivos puede reducir el grado de bienestar. Katz, M. L.: "Price Discrimination and Monopolistic Competition”, 1984, pp. 1453-1472.

Armstrong y Vickers utilizan un modelo innovador -las empresas les venden a los consumidores "excedentes del consumidor" independientemente de los productos y servicios de los que crean esos excedentes - para evaluar los efectos en bienestar de diversas formas de discriminación de precios en una amplia variedad de estructuras de mercado —incluida la competencia perfecta. Descubren que la discriminación de precios en mercados competitivos generalmente, aunque no siempre, incrementa los beneficios del consumidor, pero se trata de un ejercicio enteramente abstracto. No proporcionan pistas acerca de las estructuras institucionales en que se genera o mantiene la discriminación. Armstrong, M. y J. Vickers: “Competitive Price Discrimination”, 2001, p. 579. 
bienestar”), aunque sí transferirá riqueza desde los consumidores hacia sí mismo (lo cual podría tener efectos políticos o sociales que motivarían una intervención). Y una discriminación de precios menos que perfecta permite a menudo, si no casi siempre, que un monopolista suboptimice creando más productos que los que generaría a un precio único. Pero la discriminación de precios perfecta es extremadamente difícil de lograr en la práctica, y los monopolistas no regulados que discriminan precios casi siempre fijan sus tarifas de una manera en que se reduce la producción y el bienestar en comparación con los resultados que se obtienen bajo condiciones de competencia. Permitir que estos monopolistas discriminen los precios ha sido por lo general descrito como "menos malo" que imponer una solución de precio único, pero se ha solido suponer que se requiere al menos algún grado de poder de mercado para mantener la discriminación de precios en equilibrio ${ }^{4}$.

En este artículo no me referiré a la línea de argumentación tradicional, aunque por cierto en términos generales estoy de acuerdo con sus principios. A diferencia de lo planteado en ella, aquí no pretendo responder a la pregunta tradicional: "dada la existencia del poder de mercado, ¿puede la discriminación de precios aumentar la eficiencia?”. Antes bien, abordo la siguiente interrogante: "dada la existencia de la discriminación de precios, ¿podemos presumir la existencia del poder de mercado? La suposición de que podemos dar por sentada la existencia del poder de mercado dondequiera que encontremos discriminación de precios está implícita en gran parte de las publicaciones sobre políticas de competencia.

Un ejemplo típico en que se vincula el poder monopólico con la discriminación de precios puede encontrarse en un reciente Informe Especial del Consejo de Investigación sobre el Transporte presentado ante el

${ }^{4}$ La postura convencional en cuanto a que la discriminación de precios supone poder de mercado está resumida en Varian, H.: "Price Discrimination”, 1989, p. 599, donde se señala que "En primer lugar, la firma debe contar con cierto grado de poder de mercado”. En un artículo posterior, Varian analiza la aplicación y las repercusiones en el bienestar de la discriminación de precios en industrias con costos marginales decrecientes o muy bajos. Varian, H.: "Differential Pricing and Efficiency", en http:// www.firstmonday.dk/issues/issue2/different/index.html (visitado por última vez el 3 de diciembre de 2001). Sin embargo, su discurso es ambiguo en cuanto a las condiciones de competitividad necesarias para mantener la discriminación. Al parecer sugiere que esta discriminación se limita a situaciones de bienes o servicios cuasi-públicos con una razón costos fijos-costos variables inusualmente alta, mientras que en este artículo se sostiene que la existencia de costos comunes significativos y la consiguiente fijación de precios discriminatoria es una situación normal en mercados donde no existe poder de mercado.

La mayoría de los economistas convendrían en que, si se pudiera eliminar el poder de mercado sin efectos secundarios negativos, esa alternativa de política sería preferible a permitir que un monopolista discrimine los precios. 
Congreso estadounidense, que defiende la idea de proceder a evaluar la política de competencia aplicada en la industria de las aerolíneas ${ }^{5}$. Refiriéndose a la discriminación de precios en las aerolíneas como una forma de precios de Ramsey ${ }^{6}$, un tipo de discriminación de precios beneficioso que ha gozado de aceptación por mucho tiempo, el informe señala que "En el largo plazo, para mantener un esquema de precios como ése se requiere normalmente contar con una regulación pública o con poder monopólico para imponer una barrera de entrada"7.

\section{DESARROLLOS MODERNOS DE LA TEORÍA}

Durante la última década, el trabajo realizado por los economistas ha extendido el concepto de discriminación de precios a situaciones en que no existe poder de mercado ${ }^{8}$. Baumol plantea un caso en que firmas que desarrollan un solo producto tienen distintas curvas de costos, lo cual hace necesario que la producción eficiente sea compartida entre ellas en un equilibrio que requiere discriminación de precios (pero no fijación de precios sobre el costo marginal) ${ }^{9}$. Prescott ${ }^{10}$ y Eden ${ }^{11}$ han observado que la discriminación y la dispersión de precios pueden darse en competencia. Asociado a este tipo de discriminación de precios puede existir un equilibrio con dispersión de precios, en el que todas las firmas en competencia cobren precios discriminatorios, pero la combinación de precios varía de una empresa a otra. Dana ha extendido este modelo a la manera en que las aerolíneas gestionan la capacidad en condiciones de demanda incierta, y ha advertido la aparente paradoja de que a medida que aumentaba la competiti-

\footnotetext{
${ }^{5}$ National Research Council, Transp. Research Bd.: Entry and Competition in the US. Airline Industry: Issues and Opportunities, 1999, pp. 25-26.

${ }^{6}$ Véase más abajo, nota 25.

${ }^{7}$ National Research Council, Transp. Research Bd.: Entry and Competition in the US. Airline Industry: Issues and Opportunities, 1999, p. 26.

${ }^{8}$ Anteriormente, Borenstein postuló que la discriminación de precios puede existir bajo condiciones de competencia monopólica, con costos completamente separables y cero renta. Mi planteamiento aquí es más general, por cuanto afirmo que el fenómeno puede darse incluso cuando las firmas son tomadoras de precios, y que éste se vincula a la recuperación de los costos comunes, el caso más habitual. (En contraste con el otro trabajo citado aquí, a Borenstein no le resulta fácil demostrar la existencia de un equilibrio, pero utiliza técnicas empíricas para sugerir que su resultado es robusto). Borenstein, Severin: "Price Discrimination in Free-Entry Markets”, 1985, p. 380.

${ }^{9}$ Baumol, William J.: "Predation and the Logic of the Average Variable Cost Test”, 1996, pp. 49, 65-69.

${ }^{10}$ Prescott, E. C.: "Efficiency of the Natural Rate”, 1975, p. 1129.

${ }^{11}$ Eden, Benjamin: "Marginal Cost Pricing When Spot Markets are Complete", 1990, p. 1293.
} 
vidad de la industria que él estudió (las aerolíneas), la dispersión de precios parecía aumentar. Al mismo tiempo, observa que hay otros rasgos discriminatorios en la fijación de precios de las aerolíneas en una situación de competencia, los que, según parece, tienen su origen en otro ámbito. Él describe su marco de referencia como "demasiado sencillo para explicar satisfactoriamente la fijación de precios en aerolíneas u hoteles, aunque informativo"12. Dana profundiza su análisis — aún bajo condiciones de demanda incierta - para abarcar los sistemas de yield management (gestión del rendimiento) en los que se les asignan asientos a diversos clientes en distintos momentos y a diferentes precios, y encuentra que hay muchas circunstancias bajo las cuales este mecanismo resulta eficiente. Luego previene que "el modelo [...] sirve de advertencia adicional contra el uso de la dispersión de precios o yield management como evidencia de discriminación de precios o poder de mercado". Asimismo indica que "quienes formulan las políticas deberían considerar otras evidencias de poder de mercado antes de concluir que el comportamiento que parece ser discriminatorio atenta contra la competencia"13.

En una explicación de los equilibrios discriminatorios que llega a una conclusión análoga a la obtenida aquí, pero que se concentra en la oferta y no en el precio, Carleton sostiene que, por los costos de transacción, equilibrar mercados a un precio único puede no ser óptimo cuando existe una variación estocástica (aleatoria e impredecible) en la demanda entre los compradores $^{14}$. Las fluctuaciones en la demanda pueden hacer difícil o imposible la tarea de encontrar un precio único que permita recuperar eficientemente los costos que se mantienen de un período a otro (una forma de costos comunes). En tales circunstancias, puede que un productor escoja un precio que recupere el costo total bajo ciertos estados de demanda y evite aceptar nuevos clientes al tiempo que distribuye la demanda entre los actuales clientes según las características que se presumen o ya se conocen de su demanda. En ese caso puede existir un equilibrio de oferta discriminatorio, análogo a un equilibrio de precios de Ramsey, como una manera de recuperar costos comunes a más de un período.

En otro trabajo que se refiere a un aspecto del fenómeno considerado en este artículo, Klein ${ }^{15}$ ha sostenido, en el contexto del caso Ko-

12 Dana, James D.: “Advance Purchase Discounts and Price Discrimination in Competitive Markets”, 1998, pp. 395, 396.

${ }^{13}$ Dana, James D.: "Using Yield Management To Shift Demand When the Peak Time Is Unknown”, 1999, pp. 456, 473.

${ }^{14}$ Carleton, Dennis W.: "The Theory of Allocation and its Implications for Marketing and Industrial Structure: Why Rationing Is Efficient”, 1991, p. 231.

${ }^{15}$ Klein, Benjamin: "Market Power in Antitrust: Economic Analysis after Kodak", 1993, pp. 44, 71-85. 
$d a k^{16}$ sobre leyes antimonopolio, que la existencia de un acuerdo vinculante para segmentar a los clientes no era ineficiente ni tampoco constituía evidencia de poder de mercado por parte de Kodak. Él argumenta que muchas firmas enfrentan una curva de demanda con pendiente negativa, pero carecen de poder de mercado en cualquiera de los sentidos habituales o prácticos del término, y que segmentan a los clientes mediante variaciones en las características y disponibilidad de los productos ${ }^{17}$. Luego continúa su exposición con un análisis razonado de la práctica de Kodak de hacer que sus clientes se vean obligados a usar repuestos de esa marca, la cual no depende del poder de mercado. Klein rechaza la definición histórica de poder de mercado, señalando que incluso si la heterogeneidad de los productos y el posicionamiento de la marca implican que las firmas enfrentan curvas de demanda con pendiente negativa, aun carecen de poder para obtener rentas. El autor concluye que ninguna definición útil de poder de mercado puede basarse en el caso de firmas que enfrentan una curva de demanda horizontal como en el caso de un agricultor de trigo, que pierde todas sus ventas si fija sus precios por sobre el nivel de mercado. En un análisis ampliado de la relación entre poder de mercado y discreción en la fijación de precios, él cita con aprobación el aserto del juez Easterbrook en cuanto a que el poder de mercado consiste en "la capacidad para disminuir la producción total del mercado y así elevar los precios”18. En esa definición está contenido el que parece ser el único requisito del poder de mercado, y la adoptaré para los fines de este artículo ${ }^{19}$.

\section{UNA EXPLICACIÓN MÁS COMPLETA}

En este artículo sostengo que es posible extender la orientación básica de estos resultados modernos a una serie muy amplia de circunstancias. Sostengo que, al contrario de lo que se asevera comúnmente, la discriminación de precios, en el sentido de diferencias de precios no respaldadas por diferencias de costo identificables, es un fenómeno habitual incluso en industrias competitivas del mundo real. Si bien la discriminación de precios puede ser asociada al poder de mercado, y empleada para explotarlo

${ }^{16}$ Eastman Kodak Co. vs. Image Technical Servs., Inc., 504 U. S. 451 (1992).

${ }^{17}$ Este argumento se desarrolla en una particularmente lúcida exposición anterior de Richard Craswell y el Dr. Mark R. Fratrik, "Predatory Pricing Theory Applied: The Case of Supermarkets vs. Warehouse Stores”, 1986, p. 1.

${ }^{18}$ Ball Mem’l. Hosp. vs. Mut. Hosp, Inc., 784 F.2d 1325, 1335 (7th Cir. 1986).

${ }^{19}$ La formulación que se prefiere aquí es: "El poder unilateral o colusivo para afectar la producción industrial total de un bien o servicio”. 
y mantenerlo, en gran medida o en su mayor parte no puede por sí sola ser considerada un indicador de dicho poder.

La discriminación de precios sin poder de mercado y un equilibrio de mercado con dispersión de precios pueden tener lugar sin las funciones de costos de producción especiales postuladas por Baumol, sin los costos de transacción, costos de información, heterogeneidad de productos, emplazamiento y otros obstáculos que impiden la sustituibilidad perfecta descrita por Craswell y Fratrick en su artículo sobre fijación de precios predatorios $^{20}$, y por Klein, y sin la incertidumbre de demanda modelada por Carleton y por Dana. Se trata de características importantes de una economía del mundo real que pueden encontrarse en una gama muy amplia de contextos, pero existe todavía otro fundamento, acaso más cercano a lo universal, que respalda el fenómeno de discriminación de precios sin poder de mercado. La discriminación de precios y un equilibrio con dispersión de precios suelen darse con mucha frecuencia en mercados competitivos como una manera de recuperar los costos comunes a la producción de más de una unidad de un bien o servicio. Estos costos pueden ser comunes a la producción simultánea o a la producción a lo largo del tiempo ${ }^{21}$. En estos casos, la discriminación de precios no es más que una herramienta para distribuir los costos comunes entre los clientes de una manera tal que restrinja lo menos posible la producción ${ }^{22}$. En un mercado competitivo, todos los productores de bienes o servicios que incurran en costos comunes sustanciales tendrán que adoptar precios discriminatorios o estrategias de producto para sobrevivir.

En la práctica los costos comunes son lo suficientemente ubicuos como para que la discriminación de precios nunca se pueda considerar por sí sola como evidencia de poder de mercado, poder que debe inferirse de la estructura o del comportamiento, independiente de la segmentación del mercado. En consecuencia, aun cuando la discriminación de precios origina quejas, eso no debería dar motivo para una intervención regulatoria que aduzca razones de eficiencia basadas en el poder de mercado supuestamente asociado a ella.

${ }^{20}$ Craswell, Richard y Mark R. Fratrik: "Predatory Pricing Theory Applied: The Case of Supermarkets vs. Warehouse Stores”, 1986, p. 1.

${ }^{21}$ Tal como se emplea acá, el término "costos comunes" se refiere a costos "fijos" (o "hundidos") o costos variables en los que necesariamente se incurre de una manera que resulta común a más de una unidad de producción, sea o no del mismo producto.

${ }^{22}$ La lógica de esta aseveración resulta enteramente compatible con la argumentación sobre “conservación de la capacidad” expuesta por Dana. 


\section{A. Los modelos clásicos no reflejan adecuadamente el impacto de los costos comunes}

Aparte de la incertidumbre de la demanda y de los escollos que impiden la sustituibilidad perfecta, factores que ya hemos analizado, a los economistas les ha resultado difícil aplicar el modelo clásico de competencia perfecta a un mundo en que los costos (temporales o físicos) no se pueden separar. Al mismo tiempo que advierten la presunta eficiencia de la fijación de precios conforme al costo marginal, los economistas también se percatan con frecuencia de que los costos marginales suelen ser indeterminados y de que la fijación de precios conforme al costo marginal, aun cuando sea eficiente, tal vez no permita recuperar varias formas de costos comunes ${ }^{23}$. Puesto que la recuperación de los costos totales es requisito necesario para sostener la producción en ausencia de intervención estatal, lo anterior representa un problema.

Importantes estudios se han dedicado a analizar este problema, concentrándose en las industrias con economías de escala (es decir, industrias donde los costos unitarios promedio descienden con una mayor producción total a lo largo de toda la gama relevante). Estas industrias nunca recuperarán el costo total si fijan sus precios al mismo valor que el costo marginal. Históricamente se han propugnado diversas soluciones, desde el subsidio y la propiedad estatal — que antiguamente gozaban de mayor prestigio que hoy en día - hasta la fijación de múltiples precios. La solución que comúnmente se preconiza en la actualidad es recurrir a alguna modalidad de fijación de múltiples precios ${ }^{24} \mathrm{o}$ a la tarificación de Ramsey ${ }^{25}$, que combina múltiples precios con alguna forma de limitación de rentas mediante la regulación, de extracción de rentas mediante la tributación, o de redistribución de la renta por medio de una combinación de ambas.

La tarificación de Ramsey es una forma de discriminación de precios por medio de la cual un monopolista natural puede aumentar la producción y cubrir los costos totales sin percibir rentas monopólicas. En la tarificación de Ramsey a los consumidores se les cobran precios que son proporcionales a la razón inversa a la pendiente de sus curvas de demanda, y se impone una restricción al ingreso total a fin de impedir las utilidades monopólicas. Se cobran precios más altos a aquellos consumidores con curvas de demanda relativamente inelásticas, y precios más bajos a aquellos cuyas curvas de

${ }^{23}$ Véase Coase, R. H.: “The Marginal Cost Controversy”, 1946, p. 169.

${ }^{24}$ Ibídem.

${ }^{25}$ Para una excelente descripción breve de la tarificación de Ramsey, véase Baumol, William J., “Ramsey Pricing”, 1998, pp. 49-51. 
demanda son más elásticas. Los costos comunes y hundidos se recuperan en su mayor parte a expensas de esos consumidores que pagan los precios más altos. En un mundo perfecto que utiliza esta tarificación, a ningún consumidor dispuesto a pagar el costo marginal o una cifra superior se le cobrará jamás un precio que lo saque del mercado, y el productor recuperaría los costos de producción inframarginales ${ }^{26}$.

La tarificación de Ramsey es considerada un mecanismo benigno y preferible a sus alternativas cuando las economías de escala hacen que el monopolio y, por tanto, el poder de mercado sean inevitables ${ }^{27}$. Desde el punto de vista de las políticas públicas, la eliminación del poder de mercado carece de pertinencia, por lo que el ejercicio se convierte en uno de estática comparativa, en el que se comparan la producción y el precio en diferentes países, interviniendo en todos los casos el poder de mercado. La tarificación de Ramsey se transforma en una herramienta cuyos resultados pueden compararse favorablemente con, por ejemplo, el monopolio de precio único.

La desventaja de insistir en que la discriminación de precios sea identificada con el poder de mercado es que resulta particularmente inservible cuando se trata de interpretar muchos casos de comportamiento de fijación de precios que se observan en el mundo real. Los casos típicos de discriminación de precios que se ajustan al modelo de poder de mercado entrañan monopolios naturales o firmas con costos separables. Sin monopolio natural el paradigma discriminador de precios consiste en vender en dos precios distintos - uno de los cuales al menos supera el costo marginal- dos unidades idénticas que pueden ser producidas eficientemente por separado. La separabilidad de los costos de producción transforma el costo marginal en un factor fácilmente observable y las desviaciones en un fenómeno manifiesto. Puesto que es difícil ver cómo una firma podría tener éxito aplicando esa estrategia si no cuenta con el poder de influir en la producción total de la industria —anticipándose así a la posibilidad de que alguien más efectúe la venta al cliente "de alto precio" a un valor más cercano al costo marginal—, resulta fácil atribuir la desviación del precio del costo marginal al ejercicio del poder de mercado. Allí donde la separabilidad del costo es quebrantada por la existencia de economías de escala a lo largo de

\footnotetext{
${ }^{26}$ Véase ibídem.

${ }^{27}$ Dejo de lado el argumento teórico en favor de la susceptibilidad del mercado a la competencia, que establece una separación entre la estructura del mercado y el poder de mercado al postular la existencia de un productor que experimenta una incorporación y un retiro instantáneos y sin costos, situación que resulta muy inusual.
} 
toda la gama relevante de producción (desarrollar en conjunto más unidades del mismo producto permite reducir los costos), el monopolio natural implícito supone también poder de mercado.

\section{B. Las dificultades para asignar costos comunes}

Desgraciadamente este modelo no se ajusta con precisión a un mundo real donde muchos, tal vez la mayoría, de los productos y servicios se venden en mercados competitivos ${ }^{28}$ en condiciones en que los costos de producir eficientemente cada unidad están inseparablemente ligados a por lo menos algunos de los costos de algunas otras unidades y de otros productos o servicios. Aun cuando podemos hablar del costo marginal de producir cada paquete de productos y servicios asociados, es difícil asignar costos comunes a unidades individuales a cuya producción ellos contribuyen. Ninguna unidad puede ser producida sin los insumos comunes, pero eliminar la producción de una de las unidades producidas en común no reduciría el costo común marginal. Si bien cada unidad adicional vendida reduce el costo total promedio para ese producto - pero no para la producción total de la firma, lo cual constituiría un caso de monopolio natural-, los costos comunes incrementales no pueden asignarse a cualquier producto o clase de usuarios en particular.

Puede que sea técnicamente correcto afirmar que los costos comunes marginales de producir $n-1$ unidades utilizando los insumos comunes son los mismos que se requieren para producir $n$ unidades, o que el costo marginal de pasar de $n-1$ a $n$ unidades es cero, pero ello resulta de poca utilidad práctica al fijar el precio de las unidades. El más común de los costos comunes puede ser un factor de insumo tan trivial como el arriendo de instalaciones, el tiempo y el esfuerzo requeridos por la gestión general, los gastos generales de administración, la publicidad para promocionar la marca (en contraste con la promoción del producto), o los costos de operar una red. Ellos deben ser recuperados para que la firma continúe en el negocio. ¿̇A qué unidad o unidades deberían asignarse estos costos comunes?

${ }^{28}$ Como veremos, ello no significa negar que algunos bienes y servicios, quizás muchos, utilizan factores de insumos que producen rentas o son vendidos bajo condiciones en que las rentas son generadas por el emplazamiento, por el carácter único de la marca o por otro factor. Y algunos de estos factores pueden también contribuir a una discriminación de precios eficaz. Sin embargo, allí donde existen costos comunes, la discriminación de precios no requiere la existencia de poder de mercado, y ésta no siempre es el elemento más importante para determinar la presencia o magnitud de aquél. 
¿Deberían asignarse por igual a cada unidad? ¿Y cómo deberíamos interpretar el costo marginal de la unidad de un producto cuando contiene insumos cuyos costos son compartidos paralelamente por varios productos? ¿A qué producto debería asignarse cada costo cuando fijamos su precio de venta? ${ }^{29}$

Para dificultar las cosas, muchos de estos costos, además de ser comunes, son hundidos. En principio, de acuerdo con el análisis de estática comparativa usado para analizar la discriminación de precios, bajo condiciones de competencia a todos esos productores les debería costar recuperar sus costos hundidos. ¿Y cómo lo hacen? ¿Y cómo atraen la inversión? Este problema, bajo el rótulo de “competencia destructiva”, absorbió la atención de los reguladores a partir de la década de 1880 , cuando surgieron los casos asociados al sector de los ferrocarriles, hasta la época de las intervenciones en el negocio de los camiones de transporte, los taxis y las aerolíneas que se iniciaron durante los años de entreguerras del siglo 20. Durante la época de la Gran Depresión las intervenciones se transformaron en una práctica generalizada en todas las industrias debido a que las reducciones en la producción no implicaron necesariamente una reducción en los costos generales, provocando la inquietud que impulsó y dio vida a la National Recovery Administration*. Estos argumentos perdieron sustento en algunas industrias durante los años setenta y principios de los ochenta, pero siguen vigentes en muchos contextos de regulación estadual y federal. Por último, algunos de los costos comunes o hundidos, como I+D o publicidad para promocionar la marca, que no son específicos para un producto, tienen características de bienes públicos o de costo decreciente.

Si los costos comunes son típicos y la economía es básicamente competitiva, entonces muchos, si no la mayoría, de los productos y servicios generados con costos comunes serán desarrollados y vendidos en mercados donde el poder de mercado es inexistente o ínfimo. En la medida en que estos costos comunes representen un porcentaje insignificante de los costos totales, los precios y la producción serán impulsados por costos marginales en alza, generalmente relacionados con una creciente escasez de insumos, etc.

Sin embargo, en las empresas modernas, incluso en las de servicios, los costos comunes o hundidos corresponden a una proporción considerable del costo total ${ }^{30}$. ¿De qué manera los productores privados que afrontan

${ }^{29}$ Véase, por ejemplo, Carleton, Dennis W. y Jeffrey M. Perloff: Modern Industrial Organization, 1994, pp. 50-51, 58-62.

* Programa creado en EE. UU. bajo el amparo de la Ley de Recuperación Industrial Nacional de 1933 durante el gobierno del presidente Franklin D. Roosevelt. (N. del T.)

${ }^{30}$ Estos costos pueden incluir inversiones en capital humano, como educación, capacitación o prestigio, al igual que costos más tangibles. 
tales problemas los resuelven en esos mercados competitivos? Puesto que se ven en la obligación de recuperar el costo total a partir de los ingresos totales, ¿cómo pueden hacerlo? ¿Acaso se encuentran con precios de costo marginal en los mercados donde venden? Si los precios se basan en algo distinto al costo marginal, ¿significa eso que existe ineficiencia? Y ¿ ${ }^{\text {es posi- }}$ ble contar con precios basados en algo que no sea el costo marginal mientras hacemos frente a la competencia?

El análisis convencional es algo vago en estos respectos. Tiende a modelar un mundo dominado por costos incrementales en alza. Y contempla la posibilidad de una recuperación de los costos variables totales para productos creados con insumos comunes mediante la fijación de precios según el costo promedio variable. Por ejemplo, considera la recuperación de costos comunes en la producción homogénea, como la agricultura, eliminando a los productores incapaces de recuperar los costos totales a partir de rentas inframarginales, y asignando cualquier retorno superior a los costos a rentas de los factores. Pero muchos mercados de la vida real, o la mayoría de ellos, no se asemejan a este modelo, especialmente cuando se trata de productos individuales creados en común. Para las unidades producidas con insumos comunes no es posible determinar si acaso todas las unidades serán las mismas o serán vendidas al mismo precio si no se considera la posibilidad de que exista una estrategia dominante que comprenda un conjuntos de precios discriminatorios, tal vez respaldados por la diferenciación de productos, que también genera cero renta. Y la teoría clásica de precios no ofrece una explicación satisfactoria para la recuperación de los costos hundidos en mercados competitivos.

Otra manera habitual de explicar estos fenómenos consiste en postular la existencia de mercados monopólicamante competitivos con un modesto poder de mercado, basado en la localización o en la marca, que permita obtener rentas ${ }^{31}$. Estas rentas pueden luego financiar la recuperación de los costos hundidos, de la misma manera en que las rentas inframarginales son eliminadas al fijarse la producción total en mercados agrícolas de producción conjunta. Para una firma con un producto único lo anterior puede generar un equilibrio de cero renta, aun cuando la firma enfrentase una curva de demanda descendente. Pero esta teoría no confiere verdadero poder de mercado a la firma, pues ésta carece del poder unilateral que le permita generar rentas reduciendo la producción, o disminuir la producción para todo el conjunto de firmas cuya demanda está relacionada (producción in-

${ }^{31}$ Véase Carleton, Dennis W. y Jeffrey M. Perloff: Modern Industrial Organization, 1994, pp. 50-51, 58-62. 
dustrial). Y no es capaz de señalarnos de qué manera serán recuperados los costos comunes para producciones múltiples; por ejemplo, si acarreará una discriminación de precios y de qué manera se sostendrá. Los costos completamente separables son poco habituales, mientras que los mercados donde los productores obtienen retornos competitivos no son infrecuentes. Y lo que resulta más importante, muchos insumos relacionados con costos comunes pueden emplearse para crear una diversidad de productos en combinaciones variables, de modo que los productores y los mercados se traslapan con frecuencia y los productores no enfrentan exactamente la misma combinación de consumidores en exactamente los mismos mercados. Finalmente, el modelo requiere que las firmas afronten una situación de curvas de demanda descendentes, mientras que para muchos productos en diversos mercados las firmas son de hecho tomadoras de precios que pueden controlar su propia producción, pero deben vender al precio de mercado predominante.

\section{La discriminación de precios asigna eficientemente los costos comunes}

Lo que sostengo es que la manera más común en que los productores competitivos de bienes y servicios que comparten costos comunes recuperan esos costos es cobrando precios distintos a clientes que compran diferentes unidades o diferentes productos que comparten dichos costos. Los precios son de equilibrio del mercado, determinados por la pendiente de la demanda total de cada segmento de clientes para cada una de las unidades o productos, de manera semejante a la tarificación de Ramsey. En lugar de que el regulador imponga una restricción al ingreso total, el que la impone es el mercado. Los productores rivales les cobran los mismos precios a los consumidores situados en el mismo segmento de demanda. No hay trabas para entrar al mercado y la oferta total para todas las unidades relacionadas equivale a la producción que puede ser financiada por la suma de los ingresos disponibles en cada uno de los conjuntos de precios. Las cantidades están limitadas por la obligación de que el ingreso total equivalga al costo total (independiente de las rentas de los factores) para cada productor, y de que el último grupo de unidades reciba una renta marginal equivalente a su costo marginal de producción. No se produce ningún grupo de unidades en que el ingreso incremental no equivalga a los costos incrementales, pero distintas unidades al interior del grupo se venden a distintos precios.

Tal como ocurre en los modelos estándar de costo común, los precios están limitados por el hecho de que bajo condiciones de competencia 
las rentas seguirán generando una oferta de parte de los productores (quienes, dependiendo de circunstancias como la participación en submercados geográficos o de productos, tal vez no estén desarrollando exactamente la misma combinación de productos usando los insumos comunes) hasta que sea imposible proporcionar una unidad adicional bajo condiciones en que se pueda recuperar el costo incremental total y grupal, y una reducción del ingreso total exigirá una reducción de la producción total. El precio para cada unidad incluye todos los costos separables, más una participación en los costos comunes determinada por la elasticidad de la demanda del conjunto de clientes. El precio está sujeto a modificaciones a medida que varían la tecnología y los costos de insumos, y a medida que las variaciones en la demanda de otras unidades relacionadas afectan el ingreso y los costos totales. Por consiguiente, la producción cambia, generando un nuevo precio de equilibrio del mercado para la cantidad del producto individual desarrollado en conjunto con los demás. Para una producción eficiente se requiere usar plenamente todos los insumos comunes, excepto aquellos con carácter de bienes comunes como I+D o publicidad, para los cuales el uso pleno es en principio imposible ${ }^{32}$. Las firmas incapaces de producir eficientemente no sobreviven. Ningún productor tiene poder de mercado y no hay generación de rentas monopólicas u oligopólicas.

¿Cómo llega la industria a cobrar estos precios? Resulta difícil especificarlo con exactitud. Yo postulo que en este caso opera un juego repetido y no cooperativo cuyo resultado tiende al equilibrio, y en el cual si bien existen desviaciones del equilibrio, es muy probable que ellas sean previstas o abordadas en la próxima iteración. A los productores cuya fijación de precios no se optimiza teniendo en cuenta su función de producción y la demanda en los segmentos del mercado a los cuales están vendiendo les va mal, de modo que o se adaptan o se retiran. En el mundo real ésta es la manera en que la mayoría de los mercados alcanza el equilibrio. Las estrategias de las firmas a las que les va relativamente bien son imitadas por otras. ¿Por qué no pueden las firmas reconocer que existen combinaciones de precio y producción que generarán rentas y decidir mantener los precios y los programas de producción en esos niveles? Porque se incorporarán otras firmas, provocando un alza en la producción y un descenso en los precios, eliminando así las rentas. ¿Por qué las firmas no rebajan los precios e incrementan la producción sobre los niveles que pueden mantenerse? Porque

${ }^{32}$ Importantes elementos del costo de producción no varían con el producto. Respecto de los insumos que se comportan como bienes públicos, es preciso que ellos estén disponibles para su adquisición, o que una firma los tenga en existencia en una escala o gama suficiente como para que los costos necesarios para su producción no coloquen a la empresa en una posición desventajosa respecto de sus competidores. 
otras firmas se ven obligadas a igualar esos precios, y se percatan de que ellos no son sostenibles.

Para comprender la intuición implícita que explica el equilibrio, consideremos el mercado para la carne de vacuno: el costo de criar ganado es determinado, y esta actividad se desarrolla en un mercado competitivo. Los animales son vendidos a los faenadores a precios que tienden al equilibrio, al costo marginal de producir carne de vacuno en pie. Pero casi ningún consumidor final o intermedio compra de esta manera la carne de vacuno o sus productos derivados. En un mercado competitivo, los faenadores compran animales enteros para curtir su piel y despostarlos de una manera que permita maximizar el ingreso sujeto a limitaciones competitivas, y además cobran precios que deberán permitirles recobrar el costo total de comprar y faenar el animal. Los consumidores o los productores intermedios compran partes de animales faenados a una variedad de precios que incluyen componentes de los costos comunes y de cualquier costo separable relativo a la preparación del corte específico.

Algunas partes del animal (el lomo) son mucho más apreciadas que otras (huesos). Aunque ellas le fueron compradas al criador al mismo precio por kilo, son vendidas a los clientes a precios muy distintos por kilo. El precio para cada tipo de corte depende de la intersección de la demanda por ese corte con la oferta disponible según la cantidad de animales que puedan criarse, teniendo en cuenta los costos de determinar y mantener la segmentación del mercado. La res completa es vendida a precios que cubren el costo marginal de criar un animal y elaborar los diversos productos que de él se derivan.

Diferencias culturales o cambios en el poder adquisitivo pueden afectar o modificar los precios relativos de determinados cortes. La inmigración latinoamericana y la popularidad de la comida mexicana han elevado el precio del churrasco en relación con otros cortes. Ello debería reportar un ingreso total mayor, dando lugar a una mayor oferta de carne de vacuno e induciendo un descenso en el precio de las hamburguesas, pues se crían más reses y deben venderse sus subproductos. Otro ejemplo: las vísceras se venden más caras en países donde son más apreciadas que en los Estados Unidos, y tanto la producción total de equilibrio como los precios relativos de distintos cortes deberían variar. Por último, como puede atestiguar cualquier estadounidense que ha intentado conseguir su corte de carne preferido donde un carnicero europeo, es probable que los faenadores desposten los animales de distintas maneras a fin de maximizar su valor para los consumidores. Como los gustos cambian, la manera en que el animal es despostado y las personas a quienes se venden los cortes pueden variar. 
Como observa Carleton, en el mundo real, determinar estos cambios y definir la respuesta a ellos resulta costoso ("costos de marketing”), y dichos costos son optimizados en el proceso de segmentación ${ }^{33}$.

En definitiva, partes idénticas del animal serán vendidas a precios “discriminatorios" basados en la demanda para dichas partes, y no en su costo, el cual es en gran parte indeterminado. El ingreso total equivaldrá al costo total de procesar el animal. ¿¿ué poder de mercado o colusión respalda esos precios? Ninguno. Los productores son tomadores de precios. Si el faenador intenta cobrar un precio excesivamente alto por la carne para bistec, no logrará venderla, y su ingreso total descenderá. Si cobra menos que el precio de mercado, venderá todas sus existencias y obtendrá menos ingresos por la carne para bistec que puedan ser sumados a los ingresos por carne para hamburguesa, por huesos, etc., disminuyendo así su capacidad para costear el precio de mercado por el ganado. No puede producir más carne para bistec sin producir más carne para hamburguesas. Si relajamos el modelo de tal suerte que el productor pueda reemplazar de algún modo carne para bistec por carne para hamburguesa (tal vez comprando una raza de ganado distinta), también podrán hacerlo los demás productores (a menos que aquél posea acceso exclusivo a la tecnología y así adquiera poder de mercado), quienes igualarán los precios de dicho productor. Si el nuevo conjunto de precios para carne de bistec o hamburguesa permite una mayor oferta de ganado, ésta se expande. Si el precio sólo permite una oferta menor, ésta se contrae.

Se podría argumentar que lo anterior no constituye realmente discriminación, pues se trata de "productos diferentes". La economía carece de una definición inequívoca de "producto". Algunas definiciones giran en torno a la sustitución en la producción o en el consumo. Definen los productos señalando que los objetos físicos que son sustitutos perfectos corresponden al mismo producto. Pero éste no es un asunto exclusivamente técnico. En la medida en que los sustitutos tienen que resultar aceptables para los consumidores, dependen claramente de los gustos de éstos. Puede que algunos sustitutos de producción no sean sustitutos perfectos para algunos consumidores, y viceversa. El grado en que, por ejemplo, dos objetos o servicios son sustitutos perfectos depende, por tanto, del usuario. Para ciertos compradores no existe diferencia entre dos autos que, salvo por el hecho de diferir en su color, son idénticos. Para otros, las diferencias de

${ }^{33}$ Carleton, Dennis W.: "The Theory of Allocation and its Implications for Marketing and Industrial Structure: Why Rationing Is Efficient”, 1991. 
color determinarán variaciones en el precio. ¿Se trata acaso del mismo producto? ${ }^{34}$

Mientras algunos consumidores tengan distintas tasas de sustitución para dos productos que sean sustitutos perfectos para al menos un consumidor, existe una ambigüedad en cuanto a dónde se sitúa el "límite" del producto, y se presenta una oportunidad para que la segmentación del producto respalde la discriminación de precios.

También puede sostenerse que, como la mezcla de productos es fija, este ejemplo no viene realmente al caso. Pero, como sucede en otras industrias, puede haber algún grado de variación en la mezcla de producción, por ejemplo al dejar un corte intacto en lugar de molerlo para producir hamburguesas, o viceversa. Los ingresos totales siguen siendo el factor que define lo que puede producirse, y sólo allí donde es factible la sustitución podrían asignarse ciertos costos de insumos cuando se deja de percibir el ingreso de oportunidad de los productos. Como ocurre en muchos casos, para la producción de la mayoría de los cortes no existe un costo marginal definido que sea inferior al de criar otro animal para obtener un solo producto (como los cazadores comerciales de búfalos, de los cuales se dice que han cazado el bisonte sólo por aprovechar su lengua).

Una manera de percibir más claramente este problema es considerar todos los cortes de res como "carne de vacuno", por la que los clientes están dispuestos a pagar distintos precios. Los productores maximizan sus ingresos encontrando la combinación de cortes obtenida de un solo animal por la que los consumidores pagarán el precio más alto ${ }^{35}$. Deben proceder así para sobrevivir, pues sus competidores están actuando de la misma

${ }^{34}$ Éste es un tema aparte de si los automóviles de tamaño mediano que cuentan con un completo equipamiento se encuentran suficientemente diferenciados entre sí como para que los compradores paguen un recargo por conducir vehículos de una marca en vez de otra, permitiendo así que el modelo que más gusta genere rentas por diseño. En el mundo real puede resultar complicado distinguir entre los gastos de diseño o de producción destinados a mantener la competitividad de un producto, y los gastos que se espera generarán rentas. El ejemplo de la carne de vacuno permite abstraernos de esos asuntos.

${ }^{35}$ Como experimento de percepción, imaginemos que seccionamos el animal en cubos de $30 \mathrm{~cm}$ y luego variamos iterativamente el tamaño y la forma de los cortes, asignándoles un precio distinto hasta maximizar los ingresos. La cantidad de cortes a los que valdrá la pena etiquetar y tarificar por separado dependerá del grado en que los compradores valoren las diferencias. Para citar otro ejemplo, antes de que los estadounidenses adquirieran gustos muy refinados en el consumo de productos del mar, muchas especies de peces capturadas y/o distribuidas en conjunto eran vendidas al mismo precio que la lubina o perca de mar. Hoy en día muchas de estas especies son separadas en el mercado y se fija un precio diferente para cada una. ¿Acaso eran antes el mismo producto y ahora son productos distintos? 
manera, y no existen límites convenidos o arbitrarios para la producción industrial. La combinación difiere de un mercado a otro. En uno, muchas partes distintas del animal son trituradas para venderlas como "carne de vacuno molida". En otro, los consumidores aprecian ciertas partes que se mantienen inalteradas, las que se venden por separado a diferentes precios. La dificultad de transformar un corte en otro es lo que permite que el mercado mantenga las diferencias de precios. Ellas están limitadas por el grado en que los productos pueden ser creados prescindiendo de los costos comunes, o por el grado en que es posible transformar un producto en otro.

Los textos sobre regulaciones y políticas antimonopolio son ambiguos con respecto a qué es realmente "poder de mercado", excepto que está vinculado a los males del monopolio. Con frecuencia se lo asocia a la estructura de mercado, como sucede con el monopolio natural o el monopolio alcanzado a través de barreras de entrada o mediante prácticas predatorias. En otras ocasiones se lo asocia a la capacidad para fijar precios por encima del costo marginal, y a veces a la capacidad para generar rentas, o a niveles de rentabilidad que sobrepasan el límite competitivo. Como hemos apreciado, reducido a su expresión más elemental, el poder de mercado es la capacidad de restringir, unilateral o colusivamente, la producción total de una industria a niveles inferiores a los que podrían sustentar el ingreso total. Si bien en este sentido el poder de mercado les ofrece a los productores la oportunidad de separar los precios del costo marginal, no necesariamente se dará el caso inverso. La presencia de precios no vinculados al costo marginal no constituye un indicador de poder de mercado. Cuando se incurre en costos comunes para producir unidades no idénticas, el grado de ambigüedad del precio unitario dependerá por lo general de los costos marginales no separables. Estos costos no necesariamente se dividirán uniformemente entre los productos o unidades que los incorporan. Esta falta de un vínculo definido con el costo marginal no implica la existencia de poder de mercado. Los precios superiores al costo marginal pueden ser un indicador de poder de mercado cuando los costos son separables, pero el poder de mercado permite restringir la producción industrial de manera de aumentar los precios que equilibran el mercado. Sin la capacidad de restringir la producción industrial no hay poder de mercado.

Si en presencia de costos hundidos la recuperación de costos totales requiere de una fijación de precios de acuerdo a la demanda, entonces los productores en competencia deberán adoptar esa estrategia para sobrevivir. Si los costos comunes transforman el costo unitario en una variable indeterminada, ello no significa que los mercados no puedan equilibrarse. Sólo quiere decir que la producción industrial limitada por el costo unitario 
marginal dará paso a una producción industrial restringida por la ecuación del costo marginal total para un grupo de unidades o productos y el ingreso total que puede extraerse usando, a nivel de industria, discriminación de precios basada en la demanda. En todos los casos los productores serán tomadores de precios, no sus fijadores, aunque esta vez, tal como ocurre en los mercados de producto único de la vida real, el tanteo (tâtonnement) ${ }^{36}$ puede provocar un comportamiento que se parece a la fijación de precios, en la medida en que los productores intenten determinar de qué manera deberían combinarse los factores para crear productos y servicios, y determinar dónde se encuentra el precio competitivo para cada grupo segmentable de clientes por cada producto o servicio que desarrollan. En breve, lo que se sostiene en este artículo es que allí donde los costos comunes son considerables, cualquier equilibrio competitivo que recupere el costo total de la firma debe incluir la discriminación de precios.

\section{El equilibrio de precios y sus implicaciones}

¿Es el conjunto de precios que cobrará una industria, bajo condiciones determinadas, único? Pese a que tendríamos fundadas razones para sospechar que lo es en el caso en que todos los productores afronten exactamente los mismos costos, incluidos los de segmentación, y vendan la misma combinación de productos en el mismo mercado, no he logrado probar esta aseveración. Sólo estoy en condiciones de demostrar que las firmas serán tomadoras de precios y no perceptoras de rentas, y que los precios cobrados permitirán recuperar diferentes porcentajes de costos comunes a expensas de diversos grupos de clientes, según sean las pendientes de sus curvas de demanda. Cabe la probabilidad de que en el caso más común, en que existen costos comunes considerables que pueden emplearse para respaldar distintas combinaciones de productos vendidas por diferentes firmas a diversas combinaciones de clientes en variados mercados, no exista un equilibrio de precios único que pueda ser sostenido.

El argumento que estoy planteando aquí no aclara la interrogante sobre la unicidad del equilibrio de precios o sobre cómo es alcanzado. Consideremos una firma que produce sólo carne para bistec y carne molida en una proporción limitada por el porcentaje de carne para bistec que puede obtenerse de cada animal, con costos que difieren sólo según si la carne es

36 “Tâtonnement” es el término con que Walras designó el mecanismo mediante el cual compradores y vendedores "buscan a tientas" niveles de equilibrio entre producción y precios. Walras, Leon: Elements of Pure Economics, 1874/1984. 
cortada o molida. No podemos afirmar cuál es el costo marginal de producir carne para bistec o carne de vacuno molida. La firma debe recuperar sus costos totales para mantenerse en el negocio. Supongamos que esos costos son de US\$ 100 por animal, y que la firma vende carne para bistec y carne molida en una combinación de precios determinada por la pendiente de las curvas de demanda para ambos productos que equivaldrá exactamente al costo del animal más los costos de faenamiento, en este caso US\$ 70 por la carne para bistec y US\$ 30 por la carne molida ${ }^{37}$. Si la firma pretende vender la carne molida a más de US\$ 30 por animal, sus competidores rebajarán el precio y no se venderá nada. Si vende a menor precio, no recuperará sus costos. Pero sin duda podría sobrevivir ofreciendo el bistec a US\$ 60 y la carne molida a US\$40, y si vendiera en algunos mercados donde el bistec tuviera menos demanda, los precios de mercado podrían ser allí de US\$ 40 y US\$ 60, respectivamente. Si los mercados se traslapan, algunos productores podrían tener acceso a ambos conjuntos de precios, pero muchos tal vez no.

Si algún productor decide cobrar precios distintos de los predominantes, ya sea más altos (no será capaz de vender las unidades sobrepreciadas), ya sea más bajos (disminuirá su ingreso por unidad, pues no podrá expandir su producción de cualquiera de los bienes sin pagar por los demás), su ingreso total disminuirá y no estará en condiciones de cubrir el costo del conjunto marginal de unidades. $\mathrm{Si}$, en el curso de un juego repetido, la igualación competitiva de precios demasiado bajos hace que el ingreso industrial descienda a un nivel inferior al costo total de la industria, las firmas (actuando en forma descoordinada) tendrán que ajustar su estrategia ya sea de precios o de producción con la esperanza de corregir el desequilibrio en la iteración siguiente. Aun cuando algún productor podría experimentar con otras estrategias de precios, cobrar los precios de equilibrio del mercado es la táctica que domina al resto.

Sin embargo, el caso típico es más complejo que el ejemplo anterior de los dos productos derivados de la carne de vacuno. Así pues, no toda la producción que emplea las unidades comunes se origina en procesos productivos idénticos o es vendida en los mismos mercados, y la combinación precisa de productos que comparten costos comunes puede diferir de un productor a otro. En tales casos, la curva de demanda que se enfrenta para la producción vendida a cada segmento de clientes será la misma, pero cada productor puede crear los productos en proporciones algo distintas como reacción frente a esos precios, o crear productos adicionales utilizando al-

${ }^{37}$ Estoy suponiendo, para efectos de simplificación, que todos los animales tienen el mismo tamaño y que por tanto de ellos se obtiene la misma proporción de bistec. 
gunos de los mismos insumos, de modo que en la serie total de precios ofrecidos por diferentes productores pueda observarse dispersión ${ }^{38}$.

Es obvio que para los consumidores puede tener considerable importancia qué conjuntos de precios prevalecen en cuáles mercados, y exactamente qué serie de productos se crea usando insumos comunes. Los efectos de distribución de riqueza en personas con distintos gustos serán diferentes. Y si las diferencias de precio reflejan diferencias en los compradores que están ligadas a otras características (como raza o etnia, carácter urbano o rural), puede haber otras implicaciones sociales de los dos conjuntos de precios que el gobierno tal vez desearía tomar en cuenta por razones no económicas ${ }^{39}$.

Yo observo que podemos tener discriminación de precios y segmentación de productos incorporando variadas estrategias para la recuperación de costos comunes o hundidos en las que ninguna firma perciba rentas, y la discriminación de precios no será por sí sola evidencia de poder de mercado en ninguna de estas circunstancias. La suma de los precios debe equivaler a los costos de la firma, y ella no será capaz de recuperar estos costos sin discriminación de precios. En este modelo, el poder de mercado sólo surge cuando la colusión o una función de costo natural decreciente deja a una o algunas pocas firmas de tamaño eficiente protegidas de la entrada de competidores. En tales circunstancias, los productores individuales (o un cartel) son capaces de restringir la producción industrial. Podrían hacerlo disminuyendo la producción en determinados segmentos del mercado, o incluso redefiniendo la combinación de productos para generar mayor variedad —reduciendo la sustituibilidad para mantener la segmentación — o menor variedad de la que podría tolerarse en un mercado competitivo. Podrían hacerlo con el fin de dificultar la entrada a algunos mercados o, cuando hay proporciones de producción fijas, tal vez encuentren que les resulta más favorable destruir el producto o venderlo en mercados aparentemente menos lucrativos ${ }^{40}$. De esta manera, la discriminación de precios podría ser usada para afianzar el poder de

${ }^{38}$ Véase Dana: “Advance Purchase Discounts and Price Discrimination in Competitive Markets”, 1998, p. 416.

${ }^{39}$ Véase, por ejemplo, Ayres, Ian y Peter Siegelman: "Race and Gender Discrimination in Negotiation for the Purchase of a New Car”, 1995, p. 304.

${ }^{40}$ Una de las opiniones acerca de la crisis de electricidad de California ocurrida entre los años 2000 y 2001 es que las empresas generadoras de electricidad han descubierto que retirar del servicio algunas unidades para someterlas a mantenimiento, o dirigir la energía incremental hacia mercados con precios aparentemente menores, permitía aumentar los precios en California a un nivel suficiente para compensar a las empresas por la pérdida de producción o por la producción a menor precio. 
mercado y disminuir el bienestar. En tal situación, los precios bien podrían elevarse a un nivel superior al alcanzado en el caso competitivo de precios múltiples, y deberían subir a distintas tasas a lo largo de las curvas de demanda múltiples. La producción será fijada, entonces, en un nuevo nivel que maximice las utilidades y deje insatisfecha una demanda que podría haber sido satisfecha bajo condiciones de competencia. El bienestar disminuirá.

Lo anterior no es ciertamente óptimo, pero nótese que no podemos distinguir entre el caso del poder de mercado y el caso competitivo ateniéndonos a la segmentación o a los precios múltiples. Para detectar la presencia de poder de mercado nos veremos en la necesidad de realizar un análisis de conducta o estructura que sea independiente de la existencia de precios múltiples y que esté destinado a encontrar restricciones a la producción intencionales o por efecto.

\section{E. Mantención de la discriminación de precios}

En los mercados competitivos las empresas pueden mantener la segmentación de sus clientes con el fin de discriminar los precios de manera eficaz. Consideremos el caso en el cual lo que se está produciendo es un servicio, un bien perecible, o un bien técnicamente difícil de transferir de un usuario a otro ${ }^{41}$. En una situación como ésa no es preciso que existan diferencias físicas entre unidades del bien o servicio para permitir que prevalezca una multiplicidad de precios, y si las condiciones de producción para estas unidades suponen costos comunes, será posible observar lo que parece ser una particularmente flagrante discriminación de precios bajo condiciones competitivas (sin poder de mercado). El análisis es similar al del caso de la carne de vacuno, pero puede que aquí la apariencia o el sabor de los "cortes" no difieran mucho. Los costos comunes de la producción del bien o servicio se recuperarán mediante la segmentación del mercado. El productor que no dé este paso obtendrá un ingreso total menor. Otros productores pueden verse obligados a renunciar a la segmentación óptima al igualarse al resto para reducir las pérdidas, pero el ingreso total no respaldará la producción total. Si un productor es incapaz de sobrevivir hasta la próxima iteración, abandonará el mercado y la producción decrecerá. Si los productores se mantienen dentro, se percatarán de que existe una demanda

${ }^{41}$ Podría ser, por ejemplo, algo que se encuentra instalado permanentemente y no puede ser modificado a un precio razonable por un posterior comprador, como el color de la pintura, los frenos antibloqueo o muchos otros tipos de equipamiento opcional para un automóvil. 
insatisfecha que sólo puede satisfacerse a través de la segmentación —cobrando precios más bajos a algunos clientes y precios más altos a otrosaun si lo que se está ofreciendo a los distintos clientes es idéntico.

La situación depende en forma decisiva de la capacidad de los productores para identificar y separar a los clientes sobre la base de curvas de demanda con distintas pendientes de demanda. Se trata de una tarea costosa que limitará el grado de segmentación que vale la pena realizar. Una manera de hacerlo consiste en vender servicios en distintos mercados geográficos, incluso si no hay diferencias en el costo de prestar dichos servicios. Otra alternativa es separar los submercados por sistema de distribución o incluso por idioma ${ }^{42}$. Una tercera vía es diferenciar los servicios de manera artificial procurando deliberadamente que aquellos que se vendan a precios más bajos resulten menos atractivos para los compradores en los mercados más caros (incluso si no existe un ahorro de costo asociado al hecho de prestar el servicio menos deseable al mercado más barato), siempre que el costo incremental de crear el nuevo segmento sea menor que el ingreso incremental que se obtiene al satisfacerlo.

La misma estrategia puede ampliarse aun más con respecto a los productos. Pueden introducirse variaciones en los productos que incrementen o rebajen el valor de productos que comparten costos comunes. Mientras los consumidores sean incapaces de transformar los propios productos en la variante más o menos valiosa a un costo inferior a la diferencia de precios, los costos comunes pueden ser recuperados diferencialmente a través de la fijación de precios determinada por la demanda. Como ocurre en el caso de la discriminación de precios, la segmentación de productos puede ser una manera de recuperar los costos comunes en un ambiente competitivo, o puede ser una forma de captar rentas creando poder de mercado por medio de la diferenciación de productos. Y al igual que en la discriminación de precios a través del poder de mercado, la diferenciación de productos puede utilizarse como un método aumentador de producción para mejorar el bienestar del consumidor, o puede servir como reductor de producción, de manera de afianzar el monopolio al hacer la entrada más difícil.

Siempre que la segmentación de la demanda sea factible, el ingreso total aumenta por la segmentación y todos los productores tendrán las mismas funciones de costo (incluidos los costos comunes). Todos los pro-

42 Se ha transformado en una práctica habitual en el mercado de las aerolíneas vender ciertos pasajes a precios muy bajos a agencias o mayoristas de viajes cuya clientela es sensible al precio y habla un idioma distinto del dominante. Los agentes publicitan y comercializan sus servicios en el idioma "extranjero" sin alterar los precios a los cuales se venden pasajes a quienes hablan la lengua dominante. 
ductores contarán con incentivos similares para discriminar y tenderán a un equilibrio discriminatorio en un juego repetido y no cooperativo. Y mientras no existan restricciones de entrada o de producción, los productores serán tomadores de precios en cada submercado, y continuarán invirtiendo en producción o desarrollo siempre que el ingreso total incremental (obtenido de todas las unidades que emplean el insumo común) sea equivalente al costo incremental o lo exceda. Es necesario confirmar de manera independiente la capacidad unilateral o colusiva de limitar la producción industrial a fin de asociar esta discriminación con el poder de mercado.

\section{AEROLÍNEAS: UN EJEMPLO DEL MUNDO REAL}

La industria de las aerolíneas representa un caso particularmente notorio de este tipo de segmentación. En primer lugar, todos los asientos de un determinado vuelo se producen en común a un costo casi idéntico (dejando a un lado los aspectos relativos al tipo de servicios en cada clase $)^{43}$. En segundo lugar, los costos de infraestructura para operar la red de una aerolínea (como ejemplos pueden mencionarse los costos de terminal, control de vuelos, gastos generales y personal de mantención, y gastos generales y personal de reservas) no se generan por separado para cada pasajero, o a menudo ni siquiera para cada vuelo. En tercer lugar, el costo que supone para una aerolínea de red el hecho de transportar a cada pasajero se reparte entre viajeros con distintos itinerarios. Las redes de aerolíneas reúnen en un mismo vuelo a pasajeros provenientes de, o que se dirigen a, múltiples ciudades, para así distribuir la carga indivisible de prestar un servicio, ojalá frecuente, en mercados que no atraen a suficientes pasajeros para mantener un servicio sin escalas a un costo competitivo.

A modo de ejemplo, supongamos que Ruritania genera diariamente cierta cantidad de pasajeros hacia todos los destinos, la cual resulta suficiente para llenar un determinado número de aeronaves con una mínima capacidad eficiente, pero que no basta para ofrecer un servicio satisfactoriamente conveniente hacia un destino en particular (Metrópolis). Puede apreciarse con claridad que sólo se puede prestar un servicio útil combinando pasajeros con distintos itinerarios. La manera más eficiente de hacerlo es

${ }^{43}$ Las variaciones estocásticas en la demanda pueden crear costos de retención de inventarios y costos de oportunidad derivados de la venta prematura a precios más bajos. Si bien mecanismos como los requisitos para la compra anticipada hacen menos costoso estimar y adaptar la demanda estocástica y ajustar la demanda de último minuto y alto precio, estos ahorros de costo no son los principales factores que impulsan los diferenciales tarifarios de las aerolíneas. 
trasladar a estos viajeros a un punto central que podemos llamar Centralia (un “nodo”) y recombinarlos con otros de distinta procedencia, pero que se dirigen a Metrópolis, para de este modo formar grupos lo suficientemente numerosos como para sufragar los costos de vuelo de una aeronave con un mínimo de capacidad eficiente. Consideremos una ciudad cuyo número de habitantes permite aportar suficientes pasajeros para aplicar este sistema en varias aerolíneas en competencia, pero no tan populosa como para llenar una aeronave de tamaño eficiente que vuele con la mínima frecuencia competitiva hacia cualquier ciudad en particular. En tal ejemplo, los pasajeros podrían recibir un servicio de firmas competidoras, cada una de las cuales tendría que combinar servicios para muchos itinerarios en el mismo avión.

¿Cuál es el costo marginal de transportar a un pasajero desde Ruritania hasta Metrópolis? Sabemos cuál es el costo de volar un avión desde Ruritania hasta Centralia, pero sólo pocos de los pasajeros a bordo se dirigen a Metrópolis. Sabemos cuál es el costo de trasladar un avión desde Centralia hasta Metrópolis, pero sólo algunos de los pasajeros a bordo provenían originalmente de Ruritania (o Centralia, para el caso da lo mismo). Sabemos cuál es el costo de operar toda la red por un día o un año. Pero aparte de los costos separables, como comidas y la pequeña cantidad de combustible extra consumida al ocupar un asiento, simplemente ignoramos cuál es el costo marginal de trasladar un pasajero desde Ruritania hasta Metrópolis, entre dos puntos cualesquiera de la red.

Ahora bien, supongamos que los pasajeros varían ampliamente en cuanto a la sensibilidad al precio de su demanda de viajes. Un pasajero que viaja por motivos de negocios le asigna gran valor al tiempo y la comodidad. Desea viajar en un horario que le permita acudir a su reunión sin pérdida de tiempo, y tal vez desea combinar las escalas de un viaje de negocios de tal manera que sea necesario escoger los vuelos con mucha precisión. Está dispuesto a pagar una tarifa relativamente alta por un vuelo que parta en el horario que él prefiera. Si no puede conseguir el horario que le conviene, es probable que no desee viajar en esa compañía. En el extremo opuesto del espectro se encuentra el jubilado que conduce un automóvil. Está dispuesto a trasladarse en auto cuando se trata de viajes más cortos y la tarifa aérea es demasiado cara, y en caso de emprender un viaje más largo no tiene inconveniente en soportar varias escalas, conexiones largas, vuelos con una amplia gama de horas de despegue y otros inconvenientes con tal de ahorrar en el valor del pasaje. Sólo está dispuesto a pagar una pequeña fracción de lo que el viajero de negocios pagará por el viaje, e incluso preferiría bajarse o cambiar de avión en Desconocidolandia que volar sin escalas a Centralia, si ése es el sacrificio requerido para conseguir el precio que quiere pagar. 
En este modelo, para crear una red de dimensiones competitivas (en cuanto a ámbitos y escala) es preciso encontrar una manera de combinar la demanda del viajero de negocios con la demanda del viajero de tiempo libre, para que así sea posible prestar un servicio frecuente a precios competitivos. Esto requiere discriminar precios para ofrecer capacidad y frecuencia de manera eficiente por todos los motivos ya analizados, como también para adaptar la demanda incierta conforme al modelo de Dana ${ }^{44}$ y Carleton ${ }^{45}$. Los pasajeros dispuestos a pagar más son combinados con viajeros más sensibles al precio, y la producción aumenta en cuanto a frecuencia y ámbito para atraer a pasajeros que buscan comodidad y que están dispuestos a pagar tarifas más altas, mientras que las indivisibilidades se adecuan al ofrecer capacidad a viajeros sensibles al precio. De este modo, las firmas pueden mantener su competitividad de ámbito y a la vez continuar siendo competitivas en precios. Las empresas que experimentan indivisibilidades (costos comunes), costos hundidos y demanda incierta no pueden operar de manera eficiente sin discriminar los precios. En un mercado competitivo, todas las empresas sobrevivientes adoptarán una variante de esta estrategia, aunque los costos comunes pueden distribuirse en más de una combinación de productos y precios.

A pesar de lo anterior, existe un importante obstáculo que dificulta el logro de este resultado: puesto que (a diferencia de los cortes de carne de vacuno) el transporte ofrecido (un asiento en la cabina de clase económica en un vuelo conveniente) es objetivamente idéntico para la mayoría de los pasajeros, ¿cómo puede la empresa discriminar los precios? ¿Qué impide que el viajero de negocios vuele con tarifas de tiempo libre? Preguntarle al cliente cuál es el motivo de su viaje o cuánto está dispuesto a pagar sólo provocará una conducta estratégica. E incluso si una empresa pudiera separar de alguna manera a estos clientes, ¿cómo puede evitar que un competidor ofrezca pecios más bajos a los clientes "de alto precio”?

La manera en que la industria de las aerolíneas responde a la primera pregunta es limitando el acceso a las tarifas más bajas por la vía de imponerles condiciones que la mayoría de los viajeros de negocios considerará inaceptables. Al exigirse que los pasajes se adquieran con un adelanto de 21 días, los clientes cuyo viaje de negocios sea resultado de una necesidad de último minuto no podrán aprovechar esa tarifa. El requisito de comprar

${ }^{44}$ Ésta es la función de los sistemas de gestión de precios (revenue management systems) de las aerolíneas.

${ }^{45}$ Por ejemplo, en condiciones en que no es rentable expandir la capacidad o modificar los precios para hacer frente a la sobredemanda, una aerolínea puede dar preferencia a sus viajeros más frecuentes en las reservas de vuelos que están o estarán completamente vendidos. 
un pasaje de ida y vuelta dificulta la posibilidad de armar un itinerario incierto o complejo. Y con la condición de viajar durante una noche de sábado los hombres y mujeres de negocios que desean disfrutar de su tiempo libre los fines de semana se mostrarán reacios a aprovechar las tarifas rebajadas y sus empleadores no tendrán la intención o serán incapaces de obligarlos a usarlas.

La respuesta a la segunda pregunta es que, como se sugirió anteriormente, las empresas que no discriminan los precios no pueden ofrecer una variedad tan amplia de vuelos, ni tampoco pueden minimizar sus costos de capacidad. Obtendrán, por lo tanto, menores ingresos por unidad de capacidad ofrecida. Con el tiempo tenderán a desparecer. Como la competencia se orienta hacia un conjunto de precios que no generan ninguna renta, será preciso maximizar los ingresos (sujetos a la restricción competitiva) y minimizar los costos para mantenerse en el negocio. Puesto que la única manera de maximizar los ingresos y minimizar los costos es aplicar la segmentación de precios basada en la elasticidad de la demanda, las empresas sobrevivientes tenderán a usar esa herramienta.

Las aerolíneas de red con sistemas eficaces de gestión de precios (revenue management)* (discriminación de precios) operan constantemente con niveles más altos de ingresos por asiento/milla disponible y de factores de carga (porcentaje de asientos ocupados, lo cual supone un menor costo de capacidad por unidad de producción) que las aerolíneas que carecen de buenos sistemas de gestión de precios. Cualquier aerolínea de red puede acceder sin dificultad a dichos sistemas, ya sea mediante el desarrollo propio (alternativa que ya no es habitual en los nuevos usuarios, dado que el software tiene el carácter de bien casi público), ya sea comprándolos a diferentes proveedores.

Incluso las aerolíneas punto a punto, cuyos modelos de negocios no presentan la característica de costo común extremo propia de las aerolíneas de red, estiman que las indivisibilidades derivadas de la capacidad constante de la aeronave frente a la demanda fluctuante y al atractivo que representa para los clientes una mayor frecuencia de vuelos las obligan a discriminar los precios. Con todo, en vista de que las aerolíneas de descuento punto a punto o "de cuasi-red"46 ofrecen menos comodidades a menor costo (redes

* Revenue management se ha traducido aquí y más adelante como "gestión de precios”. (N. del T.)

${ }^{46}$ Las aerolíneas “de cuasi-red” pueden definirse como compañías cuyos sistemas de rutas permiten que los pasajeros que viajan en mercados de demasiado bajo volumen como para realizar conexiones en el servicio sin escalas, pero que no están dispuestos a incurrir en gastos considerables, consigan conexiones más convenientes. Se distinguen de las aerolíneas de red, incurren en importantes costos para lograr conexiones favorables y así atraer a clientes que pagan altos precios en mercados que no resistirán un servicio sin escalas. 
menos amplias, aeropuertos más remotos aunque menos congestionados, conexiones menos coordinadas y menos prestaciones de servicio al cliente) y limitan sus tarifas más altas para atraer a clientes de aerolíneas de red hacia su producto menos atractivo, su combinación óptima de fijación discriminatoria de precios distinta de la de las aerolíneas de red, y el conjunto óptimo de precios para las aerolíneas de red exhibe una mayor diferencia entre las tarifas más altas y las más bajas.

Si el equilibrio competitivo consiste en aplicar discriminación de precios en las tarifas de aerolíneas, ¿cómo puede la industria distinguir entre clientes de tarifas bajas y de tarifas altas? La existencia de múltiples clases de servicios ofrece una respuesta parcial. Éstas utilizan un espacio del avión creado en común, pero se les asignan precios distintos. Con todo, ello responde sólo en parte la interrogante, pues muchos pasajeros no querrán pagar por las comodidades. Y a diferencia de un corte de vacuno de alto precio, un pasaje para un viajero de negocios en clase económica no tiene por qué parecer o percibirse como algo distinto de un pasaje a precio de rebaja para un viajero de tiempo libre: los mismos asientos, las mismas comidas (o falta de las mismas), los mismos horarios de salida y llegada. La respuesta consiste en reducir el atractivo de los pasajes comprados a menor precio imponiendo restricciones que los hagan menos apetecibles para los viajeros dispuestos a pagar tarifas más altas por un viaje con mayores comodidades.

Como se señaló, la más común de esas medidas consiste en restringir el acceso a las tarifas preferenciales imponiendo la obligación de comprar pasajes por anticipado, de que el viaje sea de ida y vuelta y de que se aborde el vuelo un sábado por la noche. Si bien es cierto que los requisitos de compra anticipada y pasaje de ida y vuelta pueden también suponer un ahorro en el $\operatorname{costo}^{47}$, resulta claro que funcionan al mismo tiempo como "vallas" (como se denomina en la industria a este tipo de restricciones) para mantener alejados a los viajeros de negocios cuya demanda suele surgir con poco tiempo de aviso previo. La obligación de embarcarse un sábado por la noche carece de justificación en cuanto al ahorro de costos, pero representa una manera eficaz de ahuyentar viajeros de negocios que desean pasar el fin de semana junto a su familia o disfrutando su tiempo libre en un lugar que no sea su destino comercial. Otras prácticas de discriminación de precios consisten en limitar la notificación de disponibilidad de tarifas bajas de último minuto a determinados canales de distribución (consolidadores), o a una selección aleatoria de rutas publicitadas con muy poca antelación (tarifas de internet).

${ }^{47}$ Véase Dana, James D.: “Using Yield Management To Shift Demand When the Peak Time Is Unknown”, 1999. El requisito de que el viaje sea de ida y vuelta permite también reducir levemente los costos de transacción. 
El fenómeno de la segmentación de precios está también vinculado en grado importante a la estructura de las redes. Las redes existen para proporcionar economías de ámbito, pero además han sido estructuradas en torno a umbrales de indivisibilidad. Es decir, la extensión de una red sustentable está hasta cierto punto en directa relación con la mínima unidad de producción que genera costos unitarios acordes con la mantención del servicio. Por cierto que el tamaño de la unidad está supeditado a la tecnología, pero también depende de la estructura de precios que la red puede cobrar. Por tanto, la aparente disminución del umbral de indivisibilidad en las redes de aerolíneas para permitir el uso de pequeños aviones jet, a fin de ofrecer un servicio relativamente frecuente de jets entre puntos que previamente no podían mantenerlo, se relaciona tal vez más con el aumento de la brecha entre las tarifas más altas y más bajas cobradas en la red que con cualquier progreso tecnológico en el diseño y la fabricación de aeronaves. (Asimismo, depende en gran medida de una discontinuidad en el precio de la mano de obra que está contemplado en los contratos de trabajo característicos de las grandes aerolíneas de red.) La capacidad para segmentar y cobrar precios muy altos a determinados pasajeros significa que los viajes que a éstos les resultan extremadamente deseables (servicio directo en pequeños jets por rutas o en horarios que atraerán a los viajeros de negocios) pueden reportar ingresos unitarios muy altos que permiten compensar los altos costos unitarios.

\section{EJEMPLOS DE OTRAS INDUSTRIAS}

Es posible que este mismo fenómeno pueda apreciarse en la fijación de precios de los servicios de entrega urgente de paquetes. Dependiendo de la capacidad y de la carga en cualquier punto dado, una vez que la infraestructura para servicios de entrega de un día para otro haya sido habilitada, es probable que no resulte más costoso el servicio de entrega inmediata que el servicio de entrega en dos días, salvo en días punta. Pero antes que limitarse a fijar precios para servicios en días punta o fuera de punta, dando prioridad al servicio premium y entregando de un día para otro paquetes de entrega en dos días cuando la capacidad lo permita, la estrategia más común y eficaz consiste en incurrir efectivamente en costos adicionales para almacenar paquetes de dos días que están en ruta y así segmentar completamente el mercado ofreciendo dos "productos" coherentes a clientes con distinta elasticidad de demanda para el servicio de entrega urgente de paquetes. Existen sin duda más probabilidades de que los usuarios que escogen pagar por el nivel más bajo en el servicio, y que han 
demostrado indiferencia frente al plazo de entrega, se beneficien de cualquier variación estocástica en el tiempo de transporte, ya que ésta minimiza el costo. De igual manera, a los suscriptores de conexiones a internet de alta velocidad se les cobra una tarifa mensual por la velocidad de transferencia de datos que desean utilizar, aun cuando el "costo" (fuera del módem) de prestarles el servicio sea el mismo. El resultado de toda esta segmentación es la capacidad de respaldar grandes redes que proveen un servicio relativamente ubicuo, ofreciendo algunos precios muy bajos, otros muy altos y muchos precios intermedios.

Pero en esta estrategia no existe ningún aspecto que sea exclusivo de las aerolíneas, o de las redes, o incluso de los servicios. Funciona eficazmente en el caso de los servicios, porque el proveedor puede abstenerse de prestarle un servicio de menor precio a un cliente que él o sus competidores pueden identificar con seguridad como cliente "que paga precios altos”. Y la estrategia es de uso común en las redes, porque el alcance de una red es decisivo para su competitividad, y la segmentación de precios es fundamental para distribuir los costos comunes de una red de tal manera que permita ampliar al máximo el ámbito del servicio.

Como se señaló anteriormente, esta estrategia puede adoptarse también para los bienes transferibles, siempre que pueda encontrarse una modalidad en que a los clientes les resulte más caro modificar sus características, y de este modo se consiga que la variante con el producto de menor precio se vuelva menos deseable que la diferencia de precios. Así pues, los fabricantes de automóviles optarán por limitar la disponibilidad de equipamiento opcional que se presume resulta atractivo para los compradores que pagan altos precios, de modo que sólo pueda ser encargado dentro de una línea de productos de mayor precio que comparta costos comunes con una línea de menor precio. Los compradores sensibles al precio a quienes no les importan tanto las características, o que no son tan sensibles a la marca, reciben una oferta de precio rebajado. Los compradores a quienes les importa más qué vehículo conducen, pagan más. La instalación de accesorios de postventa es cara y a menudo menos funcional. Por ejemplo, cuando el aire acondicionado era una novedad, y el "aire acondicionado de fábrica” era mucho más apetecible que el instalado después de la compra, sólo estaba disponible en líneas de automóviles más costosos. Del mismo modo, incluso hoy en día el sistema de frenos antibloqueo no es una opción disponible en las líneas de vehículos de precios más bajos de algunos fabricantes.

¿Por qué un fabricante no pondría al alcance de los clientes estas opciones al mismo precio en sus líneas de mayor y menor precio? Incurre en costos comunes de ingeniería y producción, en la fabricación de todos los 
vehículos. Debe recuperarlos para sobrevivir, y la competencia lo obliga a distribuir estos costos entre tantos vehículos como sea posible. Como los clientes varían en cuanto al valor que les asignan a las características del vehículo, la estrategia óptima del fabricante para recuperar estos costos consiste en segmentar los clientes desarrollando tantas variantes del vehículo como sea la proporción de clientes dispuestos a pagar por ellas, y luego discriminando los precios entre las mismas. Una razón para limitar la disponibilidad de variantes deseables es ofrecer incentivos a fin de que los clientes adquieran las líneas de mayor precio. La discriminación de precios y una amplia gama de modelos les permiten distribuir los costos comunes de investigación, producción y marketing entre el mayor número posible de unidades. Una vez más, como los competidores se enfrentan con funciones de costos similares (pero no siempre idénticas), se verán obligados a adoptar soluciones similares (aunque no siempre idénticas) ${ }^{48}$.

Llevada a su extremo, esta estrategia puede encontrar expresión en la producción de bienes en que el fabricante incurre en un costo extra para ofrecer una versión de menor rendimiento. Consideremos, por ejemplo, los chips de computadores. Un chip con la misma arquitectura básica es producido con distintas velocidades de reloj o incluso (en el caso del Celeron en comparación con el Pentium III) con una función de computación desactiva$\mathrm{da}^{49}$. Los gastos en investigación y desarrollo, al igual que muchos costos de producción, son compartidos en estos chips, que son diseñados cumpliendo con una especificación de máximo rendimiento. Luego son divididos en grupos para variar la producción, o desactivados de una manera que a los consumidores les resulte prohibitivamente caro modificar, y son vendidos a precios que fluctúan ampliamente ${ }^{50}$. Hasta que el volumen permita producir un submodelo a un costo inferior al costo de oportunidad de ocupar espacio en el

${ }^{48}$ Ello explica la adquisición de fábricas de automóviles especializados por parte de grandes industrias automotrices. Los costos separables pueden recuperarse gracias a modelos y sistemas de distribución separados (o pueden ser repartidos de manera discriminatoria dentro de la línea de una marca), pero la discriminación de precios gestionada a través de marcas permite recuperar los costos comunes de la manera más eficiente.

${ }^{49}$ The San Diego Union-Tribune: "Rivals Releasing New, Cheap PC Chips”, 28 de marzo de 2000, p. 17.

${ }^{50}$ A partir de enero de 2000, los precios de Pentium fluctuaban entre US\$ 851 (800 MHz) y US\$ 193 (500 Hz). Lo que tal vez resulta más interesante es la manera en que la gama de precios se redujo en ciertos "puntos de quiebre”, como en la de 750 a 733 MHz y la de 650 a $600 \mathrm{MHz}$, lo cual sugiere la existencia de discontinuidades en los costos comunes. No sorprende que los precios de AMD exhiban progresiones y quiebres similares. Véase "Intel and AMD Cut Prices, Geck.com (25 de enero de 2000)" en http:// www.geek.com/news/geeknews/jan2000/gn2000125000505.htm (visitada por última vez el 10 de diciembre de 2001). 
chip con funciones innecesarias, los chips pueden ser realmente idénticos, excepto por el ajuste de la velocidad. A los chips más rápidos se les fija un precio considerablemente superior al de los más lentos, de modo que los clientes a quienes les importa el rendimiento pueden financiar una mayor proporción de los costos comunes que aquellos clientes preocupados de cuidar su presupuesto. Los productores rivales necesitan percibir los ingresos que les reportan los compradores que pagan mayores precios, para así mantener presupuestos competitivos de investigación y desarrollo, como también necesitan el volumen de compradores que pagan menores precios para repartir los costos de producción. Una vez más, los productores rivales se ven forzados a adoptar estrategias similares ${ }^{51}$.

Finalmente, incluso en industrias muy competitivas donde los costos no separables son bastante elevados, como los restoranes comunes y corrientes que carecen de especial prestigio, suelen adoptarse estrategias de discriminación de precios. Se ofrecen platos a la carta que no están disponibles en un almuerzo combinado de menor precio. El almuerzo es más barato que la cena. A los vinos y licores se les aplica un margen de ganancia mayor que a la comida. Mientras, por ejemplo, que la distinción almuerzo/cena puede basarse en necesidades durante horarios de punta y fuera de punta, a menudo ocurre que los restoranes que no están llenos en ninguno de esos horarios - lo mismo aquellos donde acude más gente a la hora de almuerzo que a la de la cena- aplican esta tarificación. El almuerzo es por lo regular una actividad más apresurada y no conlleva, a veces ni siquiera parcialmente, el carácter de esparcimiento que tiene la noche. Las curvas de demanda para el almuerzo y la cena tienen pendientes distintas.

Tal vez un ejemplo más palmario puede encontrarse en la industria de la comida rápida. El hecho de que un restorán de comida rápida venda hamburguesas con un margen mucho menor, en relación con el costo variable, que el obtenido en el precio de las papas fritas y las bebidas gaseosas (que se venden por separado con márgenes muy superiores al costo variable) es una práctica habitual en el negocio. ¿Cómo podemos explicar este fenómeno en un mundo sin poder de mercado?

Una manera de hacerlo es suponer que todos los restoranes tienen la misma capacidad, y que ésta es un factor restrictivo en cuanto a la cantidad de clientes a los que se puede atender por hora. Los clientes son todos idénticos, y cada uno tiene una función de utilidad separable, que genera curvas de demanda separadas para las hamburguesas y las papas fritas. La función de costos del restorán incluye un costo común fijo por mantener las

${ }^{51}$ Kanellos, Michael: “Intel: Upcoming Itanium Chip Will Hit 800 MHz”. En CNET News.Com, (7 de febrero de 2000) http://news.cnet.com/news/. 
instalaciones, más curvas separadas de costo marginal para las hamburguesas y las papas fritas. Los restoranes tienen libertad para fijar precios por separado para las hamburguesas, las papas fritas y las mesas. ¿Cuál es el equilibrio?

En este ejemplo (a diferencia del mundo real), el restorán va a estar lleno todo el tiempo, ya que se trata de un modelo perfecto de competencia sin ninguna demanda estocástica ni otra complicación. De manera que el restorán enfrenta una curva de demanda conocida para las hamburguesas: la curva de demanda de un cliente multiplicada por la cantidad de clientes. El restorán maximiza el excedente (consumidor más productor) fijando el precio de las hamburguesas en la intersección de esa curva de demanda con su curva de costo marginal para las hamburguesas, e igualmente para las papas fritas.

Agreguemos ahora una hipótesis adicional: los restoranes sólo cobran por la comida, y no por el ingreso o el uso de una mesa. Para algunos economistas esta práctica podría parecer extraña, pero es lo que se acostumbra en los restoranes del mundo real.

Supongamos que con la fijación de precios según el costo marginal para las hamburguesas y papas fritas el costo total resulte ser mayor que el ingreso total. Entonces, para cubrir los costos, los restoranes suben los precios. ¿Cómo lo hacen?

Aún desean maximizar el excedente total, sujetos a la nueva limitación. Supongamos que la demanda de papas fritas es muy inelástica y la de hamburguesas muy elástica. Un aumento de $10 \%$ en el precio de las hamburguesas generará, por tanto, un elevado costo por dejar de producir, mientras que un alza de $10 \%$ en el precio de las papas fritas generará un bajo costo por dejar de producir. Así pues, minimizan la pérdida de eficiencia aumentando considerablemente el precio de las papas fritas y sólo un poco el de las hamburguesas. De esta manera cubren sus costos totales proporcionando a los clientes un excedente mayor que el obtenido con cualquier otro patrón de precios que permita cubrir dichos costos. Lo propio ocurriría si la tarifa de entrada hubiera sido negativa, excepto que en ese caso les estarían asignando a las hamburguesas un precio levemente inferior al costo marginal, y a las papas fritas un precio muy por debajo del costo marginal, de modo de incentivar a los clientes para que acudan al local ${ }^{52}$.

52 Tengo una enorme deuda de gratitud con David Friedman por este ejemplo, y lo he reproducido en gran parte usando sus mismas palabras. El profesor Friedman participó en un seminario en la Universidad de Stanford y compartió este ejemplo con el autor a través del correo electrónico. Cualquier error que se haya deslizado como consecuencia de mi revisión y adaptación del texto, o de su uso inapropiado en un contexto inexacto, es, por supuesto, de mi única responsabilidad. 
Este planteamiento explica la existencia de precios no proporcionales al costo marginal en una industria competitiva. No requiere supuestos fuertes, siempre que exista una restricción en los precios (no cobrar separadamente por las mesas). Y se podría argumentar que la restricción es razonable para los restoranes de comida rápida, dado que la ineficiencia por cliente es probablemente baja (ya que la comida rápida es barata) y el costo de supervisar las mesas y el ingreso de personas es significativo ${ }^{53}$. En la medida en que las consideraciones prácticas suelen impedir el cobro por separado de una "entrada” de manera de recuperar costos comunes, al parecer ésta constituye por lo menos una versión común del fenómeno que he estado describiendo en este artículo: el empleo de una tarificación similar a la de Ramsey en un mercado competitivo.

\section{IMPLICACIONES EN MATERIA DE REGULACIÓN}

Con el argumento precedente no se pretende negar que sea posible encontrar poder de mercado junto a mercados competitivos en un complejo ambiente de precios múltiples del mundo real. Los monopolios de aerolíneas locales pueden existir incluso allí donde los mercados globales son competitivos. El producto de una marca puede tener atributos distintivos que, a los ojos de algunos consumidores, lo convierten en un sustituto menos que perfecto del producto de otra marca, y pueden adoptarse estrategias de precios que dificultan la entrada aun si esto fuera posible con un conjunto de precios distinto. Las rentas de insumos pueden afectar la producción y el precio. Indivisibilidades de escala pueden dar lugar a que una sola empresa permanezca en el mercado o submercado, con lo cual esa empresa adquiere poder para reducir la producción a nivel local, pues la sustitución está limitada por costos de transporte, transacción o transición (como el costo hundido de desplazar a un productor monopólico cuyo monopolio se sostiene gracias a las indivisibilidades). Cuando en dichos casos entran en juego los costos compartidos, puede haber dos conjuntos distintos de precios discriminatorios, uno con rentas y otro sin ellas. Pero en cada uno de esos casos no es la existencia de precios segmentados lo que indica la presencia del poder de mercado.

${ }^{53}$ En efecto, los restoranes, cualquiera sea su clase, casi nunca cobran separadamente por las mesas, aunque en los hoteles es una práctica habitual cobrar distintos precios por las mismas comidas y bebidas preparadas en una cocina común, pero consumidas en diferentes entornos, y es normal que en Europa se cobren distintos precios por determinados productos como las bebidas cuando se consumen en la mesa o en el bar. Algunas de estas diferencias se basan en los costos, pero otras persiguen claramente reforzar la segmentación del mercado. 
En situaciones de discriminación competitiva, la competencia de precios se da al interior de clases de productos o clientes, pero está restringida a través de ellas (dentro de las fronteras económicas de la segmentación). Como veremos más adelante, las aerolíneas pueden competir por captar viajeros circunstanciales reduciendo las tarifas bajas ofrecidas en la actualidad bajo condiciones discriminatorias, pero no pueden permitirse relajar las condiciones. Por otra parte, pueden elevar o rebajar las tarifas a viajeros de negocios, sujetos a las restricciones de la competencia. Algunas fluctuaciones de los precios corresponden a experimentos para encontrar la pendiente de las curvas de demanda por segmento, y se producirían tanto si las condiciones de mercado son competitivas o no, pero otras pueden constituir una reacción frente a la competencia dentro de un segmento de precios, o pueden ser un intento por incrementar el volumen de negocios al interior de ese segmento a precios que aprovechen una ventaja de costos. Esta última puede obtenerse gracias a una mayor eficiencia o a la capacidad no utilizada que se conserva debido a las indivisibilidades, y por ende tiene un bajo costo de oportunidad ${ }^{54}$.

Para determinar si un mercado es competitivo debemos conocer el grado en que el ingreso total de una empresa está limitado por la competencia. Si todas las firmas tienen que aplicar una tarificación similar a la de Ramsey para recuperar eficientemente los costos comunes, entonces las condiciones competitivas se verán reflejadas en límites al ingreso total, impuestos por la disposición de los competidores a captar negocios en cada segmento por la vía de reducir los precios a lo largo de la curva de demanda del respectivo segmento, siempre sujetos a una restricción del costo incremental. Este proceso seguirá su curso hasta que todas las rentas monopólicas se hayan disipado, pero todavía exhibirá una multiplicidad de precios discriminatorios en cada una de sus etapas porque una estrategia de discriminación de precios permite recuperar al máximo los costos comunes bajo cualquier conjunto dado de condiciones de demanda.

Este resultado general tiene importantes implicancias de política. Explica en parte la paradoja política a que se aludió en un comienzo: las aerolíneas de red tienen muchos costos comunes, tanto transversales como temporales. Casi bajo cualquier criterio y de acuerdo con prácticamente cualquier estudio serio que se haya emprendido, la desregulación de las aerolíneas ha sido una medida muy exitosa, y los mercados en este ámbito

${ }^{54}$ Varias aerolíneas, cuyos sistemas o servicios atraen a menos pasajeros de tarifa completa y de primera clase que sus competidores, ofrecen "viajes de primera clase por el precio de clase económica”. 
son por lo general competitivos. Con todo, pese a que se cuenta con más de dos décadas de evidencias y con el beneplácito casi unánime del mundo académico, los sectores políticos y los medios de difusión no han cesado de lanzar sus críticas. Las quejas contra las aerolíneas constituyen un recurso seguro para atraer público en las audiencias del Congreso, en los discursos políticos, en los reportajes de los diarios o en los noticiarios de la televisión.

Si bien el público se queja por la actitud de las aerolíneas, la pérdida de equipajes y la impuntualidad de los vuelos, en términos objetivos se ha observado poco deterioro en estos aspectos, y en algunas áreas, como la elección del servicio o la reducción en la cantidad de itinerarios con múltiples escalas, de hecho se ha experimentado una mejoría. Si bien es cierto que las comodidades ofrecidas por las aerolíneas han disminuido, ello se debe a que, tan pronto como los viajeros tuvieron libertad para escoger, prefirieron el servicio de menor precio, con asientos más estrechos y comida de menor calidad, más que el producto anterior, que fue el resultado de la competencia por servicios a precios fijos altos que prevaleció durante el período de la regulación. La desregulación ha significado una desventaja para algunos y, al mismo tiempo, muchos han salido beneficiados; esta afirmación rige para prácticamente cualquier cambio en las políticas públicas, y no explica la intensidad, la popularidad o la persistencia de las críticas contra la desregulación de las aerolíneas.

Con el objeto de recuperar sus costos comunes y al mismo tiempo expandir sus redes para mantener la competitividad, las aerolíneas de red emprenden una vasta segmentación de mercado y de precios. Con el sistema de libertad para fijar precios aplicado durante el período de desregulación, han aumentado sustancialmente las tarifas más altas, que con frecuencia pagan los viajeros de negocios, por pasajes totalmente reembolsables que pueden comprarse por anticipado o en el aeropuerto el día en que se viaja. Junto con la baja en las tarifas para pasajes de tiempo libre, ello ha generado una brecha de una magnitud sin precedentes entre las tarifas más altas y las más bajas del transporte aéreo ${ }^{55}$. Incluso mientras las tarifas bajas continúan expandiendo de manera substancial el tráfico aéreo en general, la segmentación del mercado no deja de aumentar, y una proporción relativamente significativa y creciente del ingreso proviene de una cantidad relativamente pequeña de pasajeros. Los viajeros que pagan tarifas muy altas se sientan junto a pasajeros que pagan tarifas bajas, y reciben el

${ }^{55}$ Véase National Research Council, Transp. Research Bd.: Entry and Competition in the U.S. Airline Industry: Issues and Opportunities, 1999, pp. 22-40. 
mismo servicio a bordo habiendo comprado lo que parece ser el mismo producto. Por último, la estructura tarifaria es casi risiblemente compleja.

Motivados por la hostilidad que provoca la discriminación de precios, y apoyándose en un modelo que dice que ésta requiere poder de mercado, tanto los académicos como el público se han entregado a una búsqueda ampliamente publicitada de las fuentes del poder monopólico de la industria de las aerolíneas, que se supone sirve de sustento a la altamente discriminatoria estructura de precios que ha surgido desde la desregulación. La prueba más contundente que se ha aducido para demostrar la existencia de un considerable grado de poder monopólico es la propia estructura de precios. Incluso los acérrimos defensores de la desregulación parecen admitir que se requiere contar con algún tipo de poder monopólico para respaldar la actual estructura de precios de las aerolíneas ${ }^{56}$.

Valiéndose de este tipo de análisis, los políticos se han visto presionados para conseguir que el gobierno ejerza su poder a fin de eliminar las disparidades en la fijación de precios. Puesto que con la desregulación de las aerolíneas ha desaparecido el atractivo de la regulación directa de precios, el organismo administrativo y el Congreso han estado procurando identificar medidas correctivas que puedan aplicarse a las presuntas fuentes del poder monopólico que han sido "descubiertas", sin necesidad de "reregular". Ante el peso de la evidencia sobre la estructura de precios, incluso los académicos y los analistas de políticas públicas, que por lo general propugnan la desregulación de las aerolíneas, se han visto en la obligación de dedicar sus energías a tratar de determinar cómo se pueden suprimir los elementos que sustentan el monopolio y al mismo tiempo conservar los beneficios que la libre entrada y la libertad de precios le han reportado al público ${ }^{57}$.

Desde el punto de vista del regulador, la importancia de toda esta situación es que el sistema de fijación de precios que hemos descrito plantea un dilema clásico y políticamente manifiesto. Los diferenciales muy amplios de precios discriminatorios sirven de respaldo a redes en mayor escala, donde el ingreso total equivale al costo total y cada compra es voluntaria. Las marcadas diferencias de precios, en especial cuando la diferencia en el servicio de a bordo es inexistente o muy pequeña como para que resulte justificada a los ojos del consumidor que paga precios altos, son fuente de quejas por odiosa discriminación. También dan pábulo a quejas de parte de empresas que ofrecen distintas mezclas de productos con diversas configu-

${ }^{56}$ Véase ibídem, p. 73.

${ }^{57}$ Véase, por ejemplo, Borenstein, Severin: "Hubs and High Fares: Dominance and Market Power in the U.S. Airline Industry”, 1989, p. 344. 
raciones de costos comunes, y a las cuales les cuesta competir con los precios del extremo inferior del rango diferenciado ${ }^{58}$. Si se considera que el regulador no está respondiendo a los reclamos, entonces la presión política va a aumentar, los reportajes periodísticos harán notar lo "absurda" e injusta que resulta la amplia disparidad en las tarifas pagadas por los clientes, y el regulador acabará prestando testimonio ante el Congreso y será blanco de recriminaciones de parte de los representantes de clientes que pagan tarifas altas, muchos de los cuales a su vez representan a ciudades previamente subatendidas que han comenzado a recibir un nuevo servicio basado en la estructura de precios discriminatorios. Las quejas de abuso "monopólico” se extenderán y se exigirá que se tomen medidas.

\section{USO INADECUADO DE LA DISCRIMINACIÓN DE PRECIOS EN EL ANÁLISIS DE LA COMPETENCIA}

Un ejemplo notable de estos intentos descaminados por eliminar el poder monopólico se observa en las acusaciones de práctica predatoria que han sido formuladas por las aerolíneas recién incorporadas y que procuran competir con las aerolíneas de red, muchos de cuyos costos tienen el carácter de costos comunes. El escenario habitual es aquel en que un potencial competidor se incorpora a un segmento del sistema de una aerolínea de red donde se discriminan los precios, cobrando en algunos casos tarifas muy inferiores a las que predominaban antes de su ingreso. Percibe su oportunidad de competencia como la posibilidad de rebajar las tarifas que la aerolínea de red está cobrando a sus clientes con menos elasticidad de demanda con respecto al precio en ese segmento de la ruta, y/o de relajar las condiciones que la aerolínea de red impone a los clientes de tarifas bajas a fin de disminuir su atractivo para los viajeros menos sensibles al precio, a expensas de los cuales la aerolínea pretende recuperar una mayor proporción de sus costos comunes. La aerolínea de red iguala esas tarifas, aun cuando el promedio de sus costos unitarios sea superior a los de la compañía recién incorporada, y expande la capacidad de sus aeronaves para adecuarse al aumento en la demanda con las nuevas tarifas. Como ahora no existen incentivos para cambiar de compañía aérea, muchos clientes locales se mantienen en la aerolínea de red. La empresa recién incorporada se ve en la obligación de retirarse del mercado, y la aerolínea de red vuelve entonces a situar sus tarifas en el nivel anterior.

${ }^{58}$ Los costos promedio de estas firmas son por lo general menores que los de sus competidores, lo cual las lleva a calificar de "predatorios" aquellos precios con los que les resulta difícil competir. 
Las consiguientes quejas por práctica predatoria pueden ventilarse en los tribunales invocándose la legislación antimonopolio ${ }^{59}$, o dentro de un marco administrativo ${ }^{60}$. En cualquiera de ambos casos se ciñen al mismo esquema básico. Se alega que se está ejerciendo poder de mercado, y se intenta fundamentar esa aseveración apuntando a la existencia de una estructura de precios discriminatorios. Se acusa a la aerolínea de rebajar los precios a un nivel inferior al "costo” para igualar las ofertas de la competencia, y de expandir su capacidad de pasajeros para adaptarse al tráfico aun cuando en la ruta "se esté perdiendo dinero" con la tarifa más baja, para luego volver a elevar las tarifas a niveles monopólicos una vez que la empresa recién incorporada ha abandonado el mercado. Estas reclamaciones presentan cierta plausibilidad a primera vista, por lo que han captado la atención de funcionarios públicos y periodistas, pero hasta ahora éstas no han sido advertidas por los jueces.

Como se analizó anteriormente ${ }^{61}$, la aerolínea de red vuela a cualquier par de ciudades, dentro de un esquema de servicios que conecta una ciudad con un nodo en el cual pueden realizarse conexiones hacia muchos otros puntos de la red. El servicio se presta en un mercado específico, digamos $A-B$, usando costos comunes, y el servicio desde $A$ hasta Londres, Nueva York, Los Ángeles, Tokio y los cientos de otras ciudades es atendido por conexiones desde su nodo. La aerolínea de red compite con otras aerolíneas similares en muchos itinerarios, y no genera rentas monopólicas de sus actividades en red ${ }^{62}$. Cualquier aeronave que vuele entre las dos ciudades transporta pasajeros con muchos itinerarios distintos. El costo incremental de trasladar a cada pasajero es bajo. Las aerolíneas crean una estructura de precios que recupera los costos comunes de la red a expensas de los pasajeros, sobre la base de la elasticidad de su demanda. Al calcularse la elasticidad de la demanda se tiene en cuenta el valor que el pasajero le asigna al viaje, como también todas las alternativas de que éste dispone, incluido el servicio prestado por otras aerolíneas, por otros medios de transporte, al igual que la posibilidad de posponer o suspender el viaje. Como hemos apreciado, esta estructura de precios discriminatoria será adoptada por todas las aerolíneas de red, y sus ofertas competitivas en los mercados en que se enfrentan permitirán garantizar que no se generen rentas monopóKan. 2001).

${ }^{59}$ Véase, por ejemplo, United States vs. Am. Airlines, 140 F. Supp. 2d 1141 (D.

${ }^{60}$ Véase en general Department of Transportation, Docket No. Ost-98-3713, Policy Statement Regarding Unfair Exclusionary Practices-Statement of Enforcement Policy Regarding Unfair Exclusionary Conduct (1998).

${ }^{61}$ Véase más arriba Parte IV.

${ }^{62}$ Ello no equivale a decir que no genere rentas monopólicas en ningún sector, sólo que éstas no resultan atingentes a su comportamiento en este ejemplo. 
licas. La estructura de precios debería maximizar los ingresos sujetos a las restricciones competitivas.

Cuando se incorpora una nueva empresa, la aerolínea en red que ya operaba en el mercado debe efectuar el siguiente ejercicio de reoptimización: primero, tiene que preguntarse si igualar los nuevos precios o abstenerse de hacerlo redundará en pérdidas de recursos que la obligarían a renunciar a la conexión con la red. Puesto que eliminar el servicio entre $A$ y $B$ significaría suprimir el servicio entre $A$ y la gran cantidad de otras ciudades conectadas a ese punto a través de $B$, con lo cual la aerolínea no sólo perdería ese ingreso sino que disminuiría el valor de la red en todos los demás puntos a los que vuela, la optimización de la aerolínea de red casi nunca supone el abandono de los tramos del sistema.

En segundo lugar, los ejecutivos de la red deberán preguntarse si, dado que la aerolínea permanecerá en el mercado, vale la pena igualar la tarifa del competidor. Como la nueva tarifa cubre los costos totales de la empresa recién incorporada, es muy improbable que una aerolínea que ya esté volando hacia ese punto como parte de una red que llega a muchos otros puntos no encuentre allí una valiosa oportunidad para obtener ingresos incrementales.

En tercer lugar, debe preguntarse si el servicio que actualmente se presta puede adaptarse a la demanda creada por la nueva tarifa y, en caso contrario, si para lograrlo es preciso expandir la capacidad. En vista de que la mayoría de los costos del sistema ya se están efectuando, los costos incrementales de capacidad descienden a medida que aumenta la capacidad de las aeronaves, los costos de marketing presentan economías de escala extremas y los costos locales de terminal exhiben indivisibilidades, casi siempre convendrá expandir la capacidad para adaptarse a la demanda estimulada por la nueva tarifa.

Nótese que la aerolínea incumbente* está maximizando sus esfuerzos sometida a la restricción de que la nueva tarifa local será fijada por la compañía que recién se incorpora. Por la vía de igualar el precio y expandir la capacidad, no queda en mejores condiciones que antes de que se incorporara el competidor, sólo en una situación más favorable que si no hubiera permanecido en el mercado ${ }^{63}$. La aerolínea incumbente iguala, por tanto,

* Incumbent se traduce aquí y más adelante como "incumbente”. La firma “incumbente" es la que ya operaba en el mercado (N. del T.).

${ }^{63} \mathrm{Si}$ la tarifa más baja hubiera sido más rentable en primer lugar, el maximizador de red la hubiera cobrado. Por cierto que a veces el incumbente descubre que sus pronósticos de demanda o costo eran erróneos, y que con la nueva tarifa obtiene mejores resultados que los previstos. En tal caso, la incorporación ha revelado información que antes no era evidente. Sin lugar a dudas, en condiciones de competencia, con redes cuyos costos totales difieren, una de las redes puede verse obligada a abandonar el mercado. Es probable que, si existe libre entrada, reaparezca una vez que la empresa recién incorporada se retire. 
la tarifa y aumenta su capacidad para hacer frente al crecimiento de la demanda.

La empresa recién incorporada suele descubrir que el mercado no es lo suficientemente amplio como para permitir su permanencia junto con la o las aerolíneas que ya operaban en el mercado, por lo que decide retirarse. Entonces la empresa que ya operaba en el mercado reoptimiza los precios y las cantidades en la red, utilizando exactamente el mismo proceso que en la iteración previa. Los precios y la capacidad regresan al nivel anterior o — si la experiencia le ha enseñado al incumbente algo acerca de la demanda o los costos - a un equilibrio distinto que considera esa información.

Desde la perspectiva del regulador, o del cliente cuyo apetito se vio estimulado por los bajos precios que luego son retirados cuando el competidor desaparece, este proceso puede parecer predatorio. Pero en este escenario no es preciso abrigar la intención de eliminar a la competencia, y el comportamiento de igualación no constituye una pérdida que deberá amortizarse echando mano de futuras utilidades monopólicas. Adviértase que los precios estaban siendo optimizados antes bajo restricciones competitivas, incluida la estructura de precios discriminatoria necesaria para maximizar los ingresos, y ahora están siendo maximizados nuevamente de esta manera. No se requiere poder de mercado para explicar o respaldar este comportamiento $^{64}$ que, por sí solo, no puede servir de fundamento para quejarse de práctica predatoria ${ }^{65}$.

Si el regulador atiende a las quejas y procura comprimir la estructura tarifaria, se dejará de prestar el servicio en algunos mercados, o bien se reducirá la frecuencia (disponibilidad y variedad). Con ello se frustrarán algunos compradores bien dispuestos ( ital vez incluso algunos de los clientes que se quejaron de los precios, pero que de todos modos pagaban por el servicio!), ya que se habrán eliminado opciones de transporte que para ellos eran preferibles a no viajar o usar otros medios. La eficiencia se verá afectada, y es probable que el regulador no se libre de las críticas, que ahora provendrán de grupos representantes de regiones o de consumidores perjudicados por la reducción del servicio. Aumentará la presión para que se ordene, y tal vez se subsidie, un aumento en el servicio, por ejemplo a comunidades más pequeñas. El regulador puede acabar testificando ante el

${ }^{64}$ Este proceso analítico no tiene por qué limitarse a las aerolíneas. Se aplica a casi cualquier industria de red y, por extensión, a cualquier firma cuyos productos comparten una cantidad apreciable de costos comunes, cuando uno de ellos experimenta una modificación en su precio inducida por factores exógenos.

${ }^{65}$ Como lo estimaron los tribunales en: United States vs. American Airlines, 140 F. Supp. 2d 1141 (D. Kan. 2001). 
Congreso y siendo objeto de las recriminaciones de los representantes de ciudades subatendidas.

Si un aumento en la discriminación de precios explica en parte por qué la desregulación de las aerolíneas ha llegado a ser tan criticada, el resto de las preguntas aún permanece sin respuesta. Si mis observaciones son acertadas, este tipo de fijación de precios es en extremo generalizada. ¿Por qué no se formulan las mismas quejas respecto de bienes y servicios cuyo precio se fija de manera similar en otros sectores de la economía? En este caso carezco de un modelo y de una explicación sistemática. Según presumo, lo anterior obedece a que las industrias no reguladas carecen de un historial de regulación que suprimió las diferencias de precios que incentivasen una mayor producción y un uso más eficiente de los insumos comunes. Por añadidura, en la mayor parte de la regulación previa para otras industrias de red, tales como electricidad y telefonía, se puso en práctica, en lugar de suprimir, la discriminación de precios (probablemente debido a que fueron percibidas como monopolios naturales en los que la tarificación de Ramsey era un método eficiente para lograr recuperar los costos), de tal manera que los clientes se habituaron a este tipo de fijación de precios. En la industria telefónica, la diferencia obligatoria entre tarifa comercial y residencial, y para llamadas locales y de larga distancia, constituye un ejemplo de esta situación. La desregulación sin duda ha permitido reorganizar y expandir muchas de estas discriminaciones, pero no ha transitado de manera tan ostensible desde la simple fijación de precios impuesta por el gobierno hasta la segmentación generalizada.

En ese sentido, el resto de la explicación para este fenómeno puede radicar en el hecho histórico de que las restricciones estatales para la segmentación de precios en industrias de red competitivas fueron eliminadas. Ésta es, desde luego, una de las principales causas de la enorme expansión de la producción observada en la industria de las aerolíneas desde que se impuso la desregulación. La consiguiente expansión tanto de escala como de ámbito (extensión de la red y mayor variedad de frecuencias) ha sido acogida con beneplácito, pero se echan de menos la simplicidad y la aparente equidad de la tarificación que actuaban como factores limitantes.

\section{CONCLUSIÓN}

Mi intención en este trabajo ha sido la siguiente: (1) explicar la prevalencia de estructuras de precios altamente diferenciadas en una economía que es por lo general competitiva; (2) establecer una separación entre los 
debates en torno a la discriminación de precios y las discusiones sobre el poder monopólico y su mantenimiento, y (3) demostrar, a modo de ejemplo, que la segmentación de precios que vemos aplicada de forma extrema en la industria de las aerolíneas corresponde a una reacción "normal” frente a la existencia de muchos costos comunes, y no sugiere en y por sí misma la presencia de poder de mercado. He mostrado que esta estrategia, que se observa en la mayoría de las áreas de la economía, es la más eficiente para lograr recuperar dichos costos. La desregulación de la industria ha permitido que esa estrategia funcione con normalidad. Lo anterior no equivale a afirmar que el poder de mercado está ausente en todos los sectores de la industria de las aerolíneas. En otra publicación ${ }^{66}$ sugerí cuáles podrían ser algunas de las fuentes de ese poder de mercado, aunque el análisis que presento en este artículo da a entender que en ese entonces no comprendí cabalmente los orígenes y efectos de la altamente diferenciada estructura de precios que aparece identificada allí67. En la industria de las aerolíneas, bajo algunas circunstancias puede existir un poder unilateral para limitar la producción de mercado, poder que también puede observarse en otras industrias tradicionales en situaciones especiales. Donde y cuando exista poder de mercado, éste puede servir de respaldo para aplicar una discriminación de precios adicional a la que existe en los mercados competitivos, y puede servir para desincentivar la incorporación de otros actores. Sin embargo, resulta claro que ni en la industria de las aerolíneas, ni en ninguna otra, la discriminación de precios per se puede ser esgrimida como una evidencia de poder de mercado que, por sí sola, justifique la intervención, y que los intentos por erradicarla acarrean generalmente más perjuicios que beneficios económicos.

Es de esperar que no prosperen las presiones políticas que se ejercen hoy en día contra la segmentación eficiente, y que los malentendidos no muevan a los académicos a propugnar y secundar la eliminación de un sistema de fijación de precios que reporta tantos beneficios. Desde luego que lo anterior no sólo es válido en el caso de las aerolíneas, sino también para la regulación y, especialmente, para la aplicación de la ley antimonopolios en general. Debemos tener en cuenta la advertencia de Ronald Coase:

${ }^{66}$ Véase Levine, Michael E.: “Airline Competition in Deregulated Markets: Theory, Firm Strategy and Public Policy”, 1987, p. 393 (1987) (reimpreso en The Economics of Transport, Herbert Mohring, ed., 1994, p. 283).

${ }^{67}$ Ahora me queda claro que gran parte del comportamiento de fijación de precios que citaba en ese artículo como evidencia de poder de mercado y de una actitud posiblemente predatoria, constituía una respuesta eficiente ante las variaciones en los precios a lo largo de las curvas de demanda de segmentos de clientes, que habían sido reveladas y determinadas por la competencia de las empresas recién incorporadas. Véase ibídem. 
Si un economista se encuentra con algo que no comprende - una práctica comercial de una u otra índole-, busca una explicación asociada al monopolio. Y como en esta materia somos muy ignorantes, la cantidad de prácticas incomprensibles tiende a ser más bien numerosa, y el recurso a la explicación basada en el monopolio suele ser frecuente ${ }^{68}$.

Demasiado frecuente, según parece.

\section{REFERENCIAS BIBLIOGRÁFICAS}

Armstrong, M. y J. Vickers: “Competitive Price Discrimination”. En Rand J. Econ., 32 (2001).

Ayres, Ian y Peter Siegelman: "Race and Gender Discrimination in Negotiation for the Purchase of a New Car". En Am. Econ. Rev., 85 (1995).

Ball Mem'l. Hosp. vs. Mut. Hosp, Inc., 784 F.2d 1325, 1335 (7th Cir. 1986).

Baumol, William J.: "Predation and the Logic of the Average Variable Cost Test". En J. L. \& Econ., Vol. 39 (1996).

"Ramsey Pricing". En The New Palgrave Dictionary of Economics and the Law, 3 (1998).

Borenstein, Severin: "Price Discrimination in Free-Entry Markets”. En Rand J. of Econ., 16 (1985).

"Hubs and High Fares: Dominance and Market Power in the U.S. Airline Industry”. En Rand J. Econ., 20 (1989).

Carleton, Dennis W.: "The Theory of Allocation and its Implications for Marketing and Industrial Structure: Why Rationing Is Efficient”. En J. L. \& Econ., 34 (1991).

Carleton, Dennis W. y Jeffrey M. Perloff: Modern Industrial Organization. New York: Harper Collins, segunda edición, 1994.

Clark, J. M.: Studies in the Economics of Overhead Costs [1923]. University of Chicago Press, 1981.

Coase, R. H.: “The Marginal Cost Controversy”. En Economica , 13 (1946).

"Industrial Organization: A Proposal for Research". En V. R. Fuchs (ed.), Economic Research: Retrospect and Prospect. Policy Issues and Research Opportunities in Industrial Organization. New York, NY.: National Bureau of Economic Research, 1972.

Craswell, Richard y Mark R. Fratrik: "Predatory Pricing Theory Applied: The Case of Supermarkets vs. Warehouse Stores”. En Case W. Res. L. Rev., Vol. 36 (1986).

Dana, James D.: "Advance Purchase Discounts and Price Discrimination in Competitive Markets”. En J. Pol. Econ., Vol. 106, No 2 (1998).

- "Using Yield Management To Shift Demand When the Peak Time Is Unknown”. En Rand J. Econ., 30 (1999).

Eastman Kodak Co. vs. Image Technical Servs., Inc., 504 U. S. 451 (1992).

${ }^{68}$ Coase, R. H.: “Industrial Organization: A Proposal for Research”, 1972, pp. 59, 67. 
Eden, Benjamin: "Marginal Cost Pricing When Spot Markets are Complete”. En J. Pol. Econ., 98 (1990).

Kanellos, Michael: “Intel: “Upcoming Ilanium Chip Will Hit 800 MHzW”. En CNT News. Com (7 de febrero de 2000) http://news.cnet.com/news/.

Katz, M. L.: "Price Discrimination and Monopolistic Competition”. En Econometrica, 52 (1984).

Klein, Benjamin: "Market Power in Antitrust: Economic Analysis after Kodak". En Sup. Ct. Econ. Rev., 3 (1993).

Levine, Michael E.: “Airline Competition in Deregulated Markets: Theory, Firm Strategy and Public Policy”. En Yale J. on Reg., 4 (1987). [Reimpreso en Herbert Mohring (ed.), The Economics of Transport, 1994.]

Prescott, E. C.: "Efficiency of the Natural Rate”. En J. Pol. Econ., 86 (1975).

The San Diego Union-Tribune: "Rivals Releasing New, Cheap PC Chips", 28 de marzo de 2000, p. 17.

United States vs. Am. Airlines, 140 F. Supp. 2d 1141 (D. Kan. 2001).

U. S. Department of Transportation (Departamento Estadounidense de Transporte): 63 Fed. Reg. 17, 919-22 (10 de abril de 1998).

U. S. Department of Transportation (Departamento Estadounidense de Transporte): Docket No. Ost-98-3713, Policy Statement Regarding Unfair Exclusionary Practices. Statement of Enforcement Policy Regarding Unfair Exclusionary Conduct (1998).

Varian, H.: "Price Discrimination”. En R. Schmalensee y R. Willig (eds), Handbook of Industrial Organization, Vol. 1. Elsevier Science Publishers B. V. 1989.

"Differential Pricing and Efficiency", en http://www.firstmonday.dk/issues/issue2/ different/index.html (visitado por última vez el 3 de diciembre de 2001).

Walras, Leon: Elements of Pure Economics. Porcupine Press, 1984 (1874).

www.geek.com/news/geeknews/jan2000/gn2000125000505.htm (visitada por última vez el 10 de diciembre de 2001): "Intel and AMD Cut Prices, Geck.com (25 de enero de 2000)".

Palabras clave: estructura de mercado y precios; leyes antimonopolios; regulación y derecho comercial; economía de la regulación.

Clasificación. JEL: D40; K20; L51. 